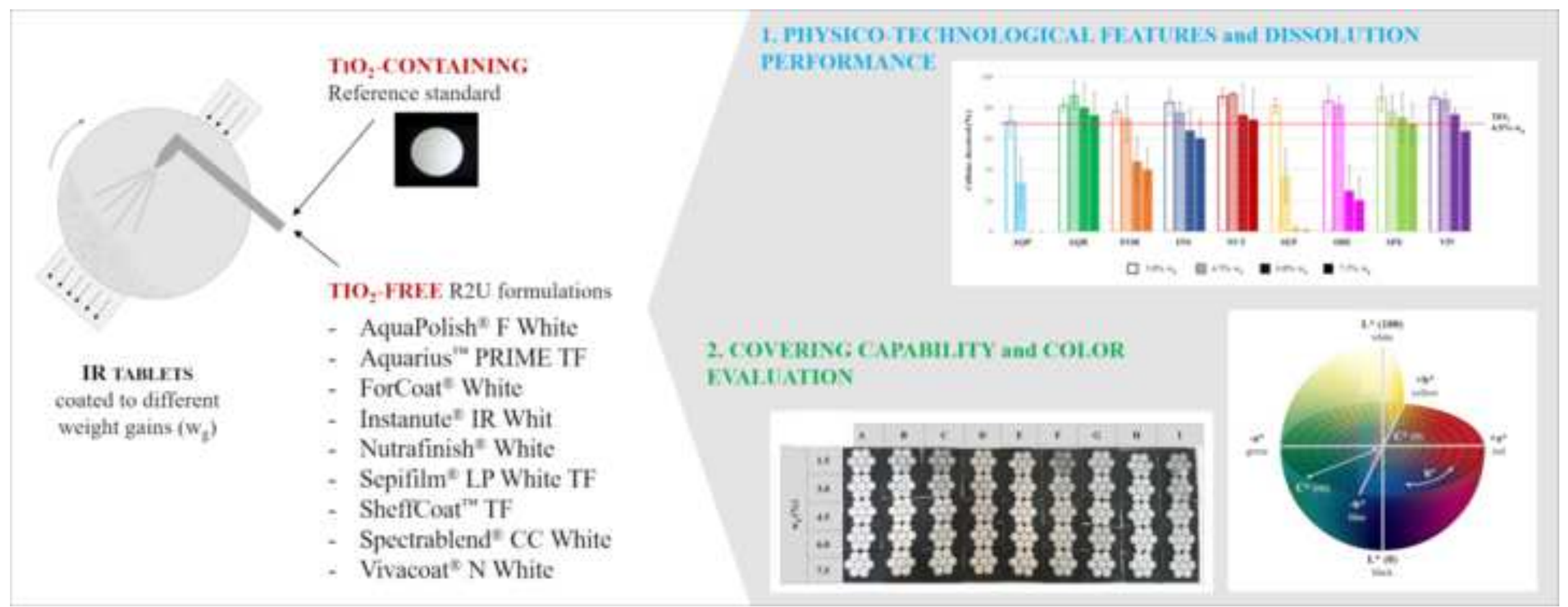

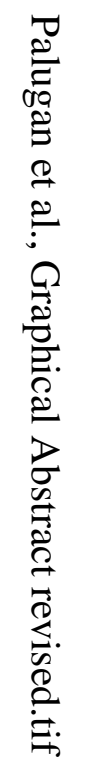




\section{What's next in the use of opacifiers for cosmetic coatings of solid dosage forms? Insights on current titanium dioxide alternatives}

Luca Palugan $^{1}$, Mattia Spoldi $^{2}$, Francesco Rizzuto $^{2}$, Norberto Guerra ${ }^{3}$, Marco Uboldi $^{1}$, Matteo Cerea ${ }^{1}$, Saliha Moutaharrik ${ }^{1}$, Alice Melocchi ${ }^{1, *}$, Andrea Gazzaniga ${ }^{1}$, Lucia Zema $^{1}$

${ }^{1}$ Sezione di Tecnologia e Legislazione Farmaceutiche “M. E. Sangalli”, Dipartimento di Scienze Farmaceutiche, Università degli Studi di Milano, 20133 Milan (MI), Italy;

${ }^{2}$ Euronovis S.R.L., 20060 Liscate (MI), Italy;

${ }^{3}$ NG Labtec S.R.L., 24124 Bergamo (BG), Italy.

*corresponding author: Email: alice.melocchi@unimi.it; Tel., 00390250324654

Keywords: dietary supplements, cosmetic coatings, titanium dioxide, spray-coating, immediate release, CIELab color space. 


\section{Abstract}

The consolidated use of coatings containing E171 (i.e. titanium dioxide, $\mathrm{TiO}_{2}$ ) as an opacifier has made the white color of the resulting dosage forms a quality standard in the pharmaceutical and dietary supplement fields. This color is also associated with the efficiency of the coating layer in protecting the substrate from the effects of UV rays. However, health risks related to diet exposure to $\mathrm{TiO}_{2}$ has recently been advanced and its addition in coating formulations has been seriously questioned. As a consequence, in principle safer $\mathrm{TiO}_{2}$-free formulations have been recently launched on the market, especially for coatings of dietary supplements. In this work, we evaluated the overall physico-technological characteristics and performance of immediate release tablets coated with a variety of commercial cosmetic formulations free of E171. Moreover, a quantitative method based on the CIELab color space was proposed for the first time for the evaluation of the covering/coloring performance of the coating formulations. Based on the results obtained, the possibility to achieve a satisfactory covering capability and a degree of white comparable to that of a standard $\mathrm{TiO}_{2-}$ containing reference with all the commercially-available ready-to-use $\mathrm{TiO}_{2}$-free products considered, without affecting the dissolution performance, was demonstrated. 
For better clarity a Glossary is reported below, defining terms and codes frequently used in the text:

- $\mathrm{TiO}_{2}: \quad$ titanium dioxide

- $w_{g}: \quad$ weight gain

- cores: $\quad$ uncoated tablets

- black cores: $\quad$ cores coated up to nominal $2 \% \mathrm{wg}$ with a polymeric formulation containing a black dye

- white-coated tablets: black cores coated up to different $\mathrm{w}_{\mathrm{g}}$ with $\mathrm{TiO}_{2}$-free polymeric formulations

- white-coated reference: black cores coated up to nominal $4.5 \% \mathrm{wg}_{\mathrm{g}}$ with a $\mathrm{TiO}_{2}$-containing polymeric formulation

- $R 2 U: \quad$ ready to use

- AQP: $\quad$ AquaPolish ${ }^{\circledR} \mathrm{F}$ White

- AQR: $\quad$ Aquarius $^{\mathrm{TM}}$ PRIME TF

- FOR: $\quad$ ForCoat $^{\circledR}$ White

- INS: $\quad$ Instanute ${ }^{\circledR}$ IR White

- NUT: $\quad$ Nutrafinish ${ }^{\circledR}$ White

- SEP: $\quad$ Sepifilm $^{\circledR}$ LP White TF

- SHE: $\quad$ SheffCoat $^{\mathrm{TM}} \mathrm{TF}$

- SPE: $\quad$ Spectrablend ${ }^{\circledR}$ CC White

- VIV: $\quad$ Vivacoat $^{\circledR} \mathrm{N}$ White 


\section{Introduction}

Cosmetic colored coatings applied onto oral solid dosage forms, such as tablets and capsules, may not only have an aesthetic function, giving a pharmaceutical elegance to the finished product, but would also (Cole et al., 1995; Felton et al., 2013; Porter et al., 2010; Rajakumari et al., 2018; Sauer et al., 2013; Seo et al., 2020):

i) increase the stability of active ingredients conveyed into the core, especially if they are lightsensitive;

ii) improve the patient/consumer compliance by masking the bad taste of ingredients and promoting swallowing of the dosage form;

iii) support the identification of the product from the user and care-giver perspective, thus increasing safety, especially in the case of treatments entailing administration of multiple dosage forms;

iv) strengthen the manufacturer's brand and reduce the risk of counterfeiting, which may represent an issue especially in the field of dietary supplements.

As a consequence of the strong potential of coated products, many companies that produce and sell excipients have been focused on launching on the market a range of R2U coating formulations (https://nutraceuticalbusinessreview.com/news/article_page/Manufacturing_pressure_accelerates_ move_to_fully_formulated_film_coatings/169691). These have been developed for being characterized by unique colors, also including the possibility of custom color adjustment according to the needs of the client companies.

Among the excipients widely used in cosmetic coating formulations - i.e. soluble polymers, antisticking agents, plasticizers and dyes - opacifiers are added to enable the attainment of nottransparent films (Cole et al, 1995; Felton et al., 2002; Rowe, 1984; Zaid, 2020). They are inorganic substances, insoluble in water and other organic solvents commonly employed in the pharmaceutical and dietary supplements fields. By reducing the penetration of UV rays through the covering film, opacifiers largely contribute to prevent photolysis phenomena and mask the appearance of the solid 
core, thus limiting the need for adding excessive amounts of dyes. Moreover, based on their refractive index, these adjuvants can also act as white pigments. $\mathrm{TiO}_{2}$, calcium and magnesium carbonate, calcium sulfate, talc and aluminum silicates as well as aluminum hydroxide represent the most commonly used opacifiers.

$\mathrm{TiO}_{2}$, also referred to as E171 in the European codification of food additives, appears as a white powder and represents the opacifier of choice in many production areas, also including paint and coloring industry. In these fields, the degree of opacity of a film is evaluated through the calculation of the so-called contrast ratio, defined as the ratio between the reflectance of the incident light measured by placing the film onto a black surface and then onto a white one (Patton, 1988; Webster et al., 2002). The contrast ratio is generally calculated as a percentage. A contrast ratio of $0 \%$ is attained in the case of completely transparent films, while a value of $100 \%$ is associated with total opacity. In this respect, dealing with films of the same thickness, while the addition of calcium carbonate or talc to coating formulations may lead to layers with a contrast ratio of about $45 \%$, that of $\mathrm{TiO}_{2}$ allows to reach values $>90 \%$ (Patton 1988).

Although the use of $\mathrm{TiO}_{2}$ was considered safe for several years, many concerns have been recently raised based on new in vitro and in vivo results (Winkler et al., 2018). DNA damages were first highlighted during in vitro studies on cells (Dunford et al., 1997). Upon exposure to UV rays, this excipient was shown to catalyze the production of reactive oxygen species, such as superoxide anion, hydroxyl radical and singlet oxygen, even in aqueous media (Konaka et al., 2001). Once internalized, $\mathrm{TiO}_{2}$ particles exhibited the ability to concentrate in the perinuclear region of cells, promoting the formation of reactive oxygen species. Further in vitro experiments proved that, even in the absence of photoactivation, nanoscale $\mathrm{TiO}_{2}$ particles (particle size $<200 \mathrm{~nm}$ ) would cause oxidative DNA damage, lipid peroxidation, micronucleus formation, creation of hydrogen peroxide and nitric oxide (Gurr et al., 2005). More recently, in a study performed by the French National Agronomic Research Institute, a reduction in T-Helper cells isolated from Peyer's patches, a marked increase in splenic $\mathrm{Th}_{1}$ / Th 17 inflammatory response and microinflammation of the colonic mucosa with formation of pre- 
neoplastic lesions were evidenced on rats being orally exposed for 100 days to $\mathrm{TiO}_{2}$ (Bettini et al., 2017). Interestingly, the daily dose administered (i.e. approximately $10 \mathrm{mg}$ per $\mathrm{kg}$ of body weight) was comparable to average diet exposure to $\mathrm{TiO}_{2}$ of children and adults due to its presence in industrially-produced foods, such as confectionary products. As a consequence of these recent findings and to ensure consumer safety, the French Government signed a decree halting sales of food containing the additive E171 starting from January 1, 2020 and until the entire 2021 (https://apps.fas.usda.gov/newgainapi/api/report/downloadreportbyfilename?filename=France\%20b ans\%20Titanium\%20Dioxide\%20in\%20food\%20products\%20by\%20January\%202020_Paris_Fran ce_5-3-2019.pdf; https://www.anses.fr/en/system/files/ERCA2019SA0036.pdf). Indeed, the decision followed the publication of an opinion by the French Agency for Food, Environmental and Occupational Health and Safety which emphasized that there was still not enough data available to carry out a proper assessment of the risks associated with the use of such an adjuvant. For this reason, it recommended to reduce the overall exposure of workers, consumers and environment to $\mathrm{TiO}_{2}$. Doubts still remain as to whether E171 would be safe for users, and these have also been pointed out also by the European Food Safety Authority (EFSA) (https://www.efsa.europa.eu/en/news/titaniumdioxide-e171-no-longer-considered-safe-when-used-food-additive; Younes et al., 2021). Actually, an updated safety assessment was published by EFSA in May 2021, taking into account all new relevant data available on $\mathrm{TiO}_{2}$ since the completion of its re-evaluation in 2016. Given the many remaining uncertainties, it was established that E171 cannot longer be considered as safe when used as a food additive. In such a scenario, a range of companies started in early 2020 to look for $\mathrm{TiO}_{2}$-free cosmetic film-forming formulations, to especially address to the dietary supplements market. In this respect, their main goal was to develop ready-to-use formulations leading to coated products having a comparable white-aspect.

Based on these premises, the aim of the present work was to evaluate commercially available cosmetic formulations containing opacifiers other than $\mathrm{TiO}_{2}$ for spray-coating of immediate-release (IR) tablets. Formulations based on low molecular weight hydroxypropyl methyl cellulose from well- 
established manufacturers of pharmaceutical and nutraceutical excipients were considered (i.e. Biogrund, Ashland, Colorcon, Ideal Cures, JRS Pharma, Kerry, Seppic, Sensient Pharma). These contained different carbonates, phosphates, polyols and cellulose derivatives, in place of $\mathrm{TiO}_{2}$ as the opacifier. Although the requirement for replacing $\mathrm{TiO}_{2}$ currently affects only the dietary supplement industry, the safety of coating formulations could soon become a strategic concern also for drug products. In addition, it is a quite common practice to use the same cosmetic formulations in both these industrial fields and, in the near future, the $\mathrm{TiO}_{2}$-free ones here studied may also be implemented in pharmaceutical processes, especially if additional worries relevant to E171 use would be raised.

Comparable coating processes were developed for all the selected coating formulations and their covering capability as well as the influence of the coatings applied on mechanical properties and performance of the final products were studied using one of the worst-case substrates, i.e. black cores. In particular, the covering capability of the coating formulations was compared to that of a $\mathrm{TiO}_{2-}$ containing standard reference in terms of color of the coated tablets and degree of white, taking advantage of a quantitative method for color measurement already used in other production sectors and based on the CIELab color space.

\section{Materials and methods}

\subsection{Materials}

Caffein (A.C.E.F, I); iron oxide black (INSTACOAT COLOR, Ideal Cures, IN); hydroxypropylmethyl cellulose (HPMC) 2910 (VIVAPHARM ${ }^{\circledR}$, JRS Pharma, D); polyethylene glycol 6000 (Lipoxol 6000 Med powder, Sasol, I); talc (Luzenac Pharma, Imerys, F); $\mathrm{TiO}_{2}$ (Aromata Group, I).

PROSOLV $^{\circledR}$ EASYtab Nutra CM (JRS Pharma, D): R2U tableting formulation containing microcrystalline cellulose, colloidal silicon dioxide, croscarmellose sodium and magnesium stearate. 
R2U coating formulations: AQP (Biogrund, D); AQR (Ashland, US-NJ); FOR (Forcoat ${ }^{\circledR}$, PL); INS (Ideal cure, IN); NUT (Colorcon, UK); SEP (Seppic, F); SHE (Kerry, US-NJ); SPE (Sensient, USWI); VIV (JRS Pharma, D).

\subsection{Methods}

\subsubsection{Fabrication of cores}

Batches of $2 \mathrm{~kg}$ of caffeine ( $16.7 \%$ by weight) and $12 \mathrm{~kg}$ of the Prosolv ${ }^{\circledR}$ EASYtab formulation were weighted (Ohaus EB series, CH) and mixed in a $50 \mathrm{~L}$ mixer (Cyclops LAB, Vima Impianti, I) for 15 min. $500 \mathrm{mg}$ tablets were prepared using a rotary press (PA20 67-51, B\&D, Italy) equipped with 20 punches (11 mm in diameter and curvature radius of $15 \mathrm{~mm}$ ); compaction force approximately $13 \mathrm{kN}$, rotation speed $25 \mathrm{rpm}$.

\subsection{Preparation of film-forming formulations}

R2U coating formulations (i.e. AQP, AQR, FOR, INS, NUT, SEP, SHE, SPE and VIV) were prepared following the instructions provided by the manufacturers. Additional formulations based on the compositions reported in Table 1 were prepared by dispersing/dissolving the previously weighted (Mettler ID1 MultiRange, Mettler-Toledo, I) components (10 or $15 \%$ solids for the black or the $\mathrm{TiO}_{2}$ containing formulations, respectively) in distilled water at $25^{\circ} \mathrm{C}$ under continuous stirring for $45 \mathrm{~min}$.

Table 1: solid composition of the coating formulations in-house prepared.

\begin{tabular}{|l|l|l|}
\cline { 2 - 3 } \multicolumn{1}{c|}{} & \multicolumn{2}{c|}{ Amount (w/w \%) } \\
\cline { 2 - 3 } \multicolumn{1}{c|}{ Component } & Black formulation & TiO2-containing formulation \\
\hline HPMC 2910 & $81 \%$ & $50 \%$ \\
\hline Talc & $/$ & $15 \%$ \\
\hline Polyethylene glycol 6000 & $9 \%$ & $10 \%$ \\
\hline Iron oxide black & $10 \%$ & \\
\hline $\mathrm{TiO}_{2}$ & & $25 \%$ \\
\hline
\end{tabular}




\subsubsection{Coating processes}

Cores were first coated up to nominal $2 \% \mathrm{wg}$ using the black formulation reported in Table 1 , to attain units characterized by a dark surface. A second coating layer based on $\mathrm{R} 2 \mathrm{U} \mathrm{TiO}_{2}$-free formulations (i.e. AQP, AQR, FOR, INS, NUT, SEP, SHE, SPE and VIV) was then applied up to different $\mathrm{w}_{\mathrm{g}}$ with respect to black cores (i.e. nominal 1.5, 3.0, 4.5. 6.0 and 7.5\% $\mathrm{wg}_{\mathrm{g}}$ ). Starting from the same black cores, a white-coated reference was also prepared coated up to $4.5 \% \mathrm{wg}_{\mathrm{g}}$ with the $\mathrm{TiO}_{2}$-containing formulation reported in Table 1.

Coating processes were performed in a perforated R\&D model pan coater (Nicomac Coating System, PC Classic 1-3-5, Nicomac, I) equipped with the smaller pan suited for processing approximately 1 $\mathrm{kg}$ of cores. Each coating process performed entailed subsequent steps: 1) loading of the cores into the pan; 2) heating of the cores; 3) coating, involving spraying of the coating formulation and drying; 4) cooling of the coated tablets. Samples (150 g) with increasing nominal $\mathrm{w}_{\mathrm{g}}$ of white-coated tablets were collected during the coating process. In Table 2 the coating parameters selected for being maintained constant with all the film-forming formulations employed are reported.

Table 2: coating parameters.

\begin{tabular}{|c|c|c|c|}
\hline & \multicolumn{3}{|c|}{ Coating step } \\
\hline & 2) & 3) & 4) \\
\hline Time (min) & 10 & 60 & 15 \\
\hline Air temperature $\left({ }^{\circ} \mathrm{C}\right)$ & $58-60$ & 58 & 25 \\
\hline Tablet temperature $\left({ }^{\circ} \mathbf{C}\right)$ & $25-43$ & $40-43$ & $30-43$ \\
\hline Nozzle pressure (bar) & & 1.0 & \\
\hline Pattern pressure (bar) & & 0.8 & \\
\hline Pan rotation speed (rpm) & 6 & 18 & 6 \\
\hline Distance nozzle-tablets $(\mathrm{cm})$ & 10 & 10 & 10 \\
\hline Coating formulation flow (g/min) & & $5-10$ & \\
\hline Inlet air flow $\left(\mathrm{m}^{3} / \mathrm{h}\right)$ & 100 & 1400 & 100 \\
\hline Outlet air flow $\left(\mathrm{m}^{3} / \mathrm{h}\right)$ & 104 & 2900 & 110 \\
\hline
\end{tabular}




\subsubsection{Characterization of uncoated and coated units}

Uncoated and coated units were checked for weight $(n=20$; Crystal 500, Gibertini, I), height and diameter ( $\mathrm{n}=20$; Digital micrometer 7002, Mitutoyo, I), crushing strength $(\mathrm{n}=10$; TBH30 Erweka, D) and friability $(\mathrm{n}=13$; EF-2 Electrolab, I). In addition, photographs were acquired using a digital camera ( $\mathrm{n}=10$; Dino-Lite Pro AM 413T, AnMo Electronics Corporation, TW).

$\mathrm{Wg}_{\mathrm{g}}$ after coating was calculated as follows:

$w_{g}=\frac{\left(w_{c}-w_{u}\right)}{w_{u}} \times 100$

Eq.1

where

$\mathrm{w}_{\mathrm{c}}$ is the average weight of units after the coating process;

$\mathrm{W}_{\mathrm{u}}$ is the average weight of units before the coating process.

Thickness of the coating layers applied onto the units was measured using a digital microscope $(\mathrm{n}=$ 10; Dino-Lite Pro AM 413T, AnMo Electronics Corporation, TW) coupled with a software for image analysis (ImageJ, NIH, US-MA); for this purpose, photographs of the cross-section of coated units cut into halves (Genius, J.S.N.Y, CN) were collected.

Disintegration time was determined using a three-position disintegration apparatus $(n=6$; DT3 Sotax, $\mathrm{CH}$ ). Each basket-rack assembly moved at a 31 cycles/min rate in a separate vessel filled with 800 mL of water kept at $37.0 \pm 0.5^{\circ} \mathrm{C}$.

The dissolution test was performed in apparatus $I I, 900 \mathrm{~mL}$ distilled water, $37.0 \pm 0.5^{\circ} \mathrm{C}, 100 \mathrm{rpm}$ $(\mathrm{n}=6$; AT7 Sotax, $\mathrm{CH})$. Fluid samples were withdrawn at fixed time points and assayed spectrophotometrically (Lambda 35, Perkin Elmer, I; $\lambda=248 \mathrm{~nm}$ ). Percentage of caffeine dissolved after 5 and 15 min of testing were calculated; by linear interpolation of the data immediately before and after the time point of interest, time to $80 \%$ caffein dissolved ( $\left.\mathrm{t}_{80 \%}\right)$ was also calculated. 
The evaluation of tablet color was carried out applying CIELab- and CIELCh-based methods as described in Section 3.2 of the Results. Top and bottom surfaces of tablets $(n=50)$ were analyzed by means of a dedicated spectrophotometer (Agera, HunterLab, VA-US). L*, $\mathrm{a}^{*}, \mathrm{~b}^{*}, \mathrm{C}^{*}$ and $\mathrm{h}^{\circ}$ parameters were measured for illuminant $\mathrm{D} 65 / 10^{\circ}$ and $\Delta \mathrm{E}^{*}{ }_{00}$ values were determined with respect to the white-coated reference. Moreover, two blind studies focused on how the white color was perceived by human eyes were carried out on white-coated tablets, involving 20 subjects under 30 years old and not affected by any visual defect. In the former study, for each coating formulation and $\mathrm{wg}_{\mathrm{g}}$ considered, white-coated tablets $(\mathrm{n}=7)$ were positioned in a flower-like pattern, named cluster. Following a table-like outline (i.e. test panel 1), for each $\mathrm{wg}_{\mathrm{g}}$ (corresponding to different rows), clusters of samples coated with the formulations under investigation were randomly positioned in columns named from A to I and delivered to the selected subjects. These were asked to re-position the clusters along each row, i.e. involving samples coated up to the same $\mathrm{w}_{\mathrm{g}}$, ranking them from the lightest to the darkest. Decreasing scores were given to each cluster based on the ranking position. Particularly, the A-I positions were normalized on a 1.1-10 scale of scores, thus resulting in 10 scores attributed to the first ranked, 8.9 to the second, 7.8 to the third, 6.7 to the fourth, 5.6 to the fifth, 4.4 to the sixth, 3.3. to the seventh, 2.2 to the eighth and 1.1 to the ninth ranked cluster. In the second study, randomly positioned clusters of white-coated tablets coated up to the same $\mathrm{w}_{\mathrm{g}}$ were shown to subjects, together with the cluster of the white-coated reference. In this case, the volunteers were required to re-position in a test panel the clusters ranking them from the most similar to the least similar to the reference. Points were given to the ranked clusters as described for test 1 . This second study was only performed for the white-coated tablets of nominal 4.5 and $7.5 \% \mathrm{wg}$.

Statistical analysis was carried out using Excel software (Microsoft, Redmont, US-WA). Data were subjected to one-way analysis of the variance (ANOVA) and relevant statistical significance was set at $\mathrm{p}<0.05$.

\section{Results}


When using $\mathrm{TiO}_{2}$ as an opacifier in cosmetic coating formulations, non-transparent films can be obtained with a typical white color highly appreciated by manufacturers and well-recognized by users so as it is currently considered a quality standard in the sector (Felton et al., 2002; Titanium dioxide for coatings - Ti-Pure ${ }^{\mathrm{TM}}$, product overview). Moreover, these characteristics were associated with the efficiency of the coating layer in protecting the substrate from the effects of UV rays. Aiming to replace this adjuvant, it would therefore be of utmost importance to be able to obtain coatings with a similar performance, not only from an aesthetic but also from a functional point of view (i.e. color and covering capacity, respectively). Moreover, the presence of the coating should not impair other quality characteristics. Accordingly, to verify this hypothesis, we have devised an experimental plan based on $i$ ) the application of increasing amounts of coating formulations, containing $\mathrm{TiO}_{2}$ or alternative opacifiers, onto IR black cores, and ii) the comparative evaluation of physicotechnological characteristics, dissolution performance, covering capability and color of the whitecoated tablets, taking $\mathrm{TiO}_{2}$-containing samples as a reference.

\subsection{Preparation and characterization of white-coated tablets}

Starting cores manufactured by direct compression were characterized by reproducible weight (average $503.14 \mathrm{mg}, \mathrm{CV}=2.58)$, high crushing strength (327 $\mathrm{N}, \mathrm{CV}=12.63)$ and average weight loss following the friability test of $0.1 \%(\mathrm{CV}=2.4)$. Accordingly, they turned out suitable as substrates for the spray-coating of a black polymeric formulation. Indeed, the attainment of a homogeneous dark surface was fundamental for enabling the evaluation of the covering capability of the film-forming formulations containing different opacifiers. $\mathrm{W}_{\mathrm{g}}$ of black cores after coating (11.01 mm, $\mathrm{CV}=0.14$ in diameter and $5.44 \mathrm{~mm}, \mathrm{CV}=0.32$ in height) was approximately $1.5 \%$ and the thickness of the black film turned out $55.38 \mu \mathrm{m}(\mathrm{CV}=20.99)$ on the top/bottom tablet surfaces and $31.52 \mu \mathrm{m}(\mathrm{CV}=20.12)$ on the lateral ones. Based on the cores' shape and preferential arrangement when tumbling, the different average thickness could be attributed to the different area exposed to spraying. Overall, coating distribution onto the cores was homogeneous and the black film 
applied showed the ability to improve the mechanical resistance of units (average weight of black cores $511.44 \mathrm{mg}, \mathrm{CV}=2.57$; crushing strength $420 \mathrm{~N}, \mathrm{CV}=9.82$; weight loss practically 0). Moreover, the black coating obtained was proven not to impair the dissolution performance of the IR cores. Indeed, the $\mathrm{t}_{80 \%}$ was found to be $4.88(\mathrm{CV}=1.68)$ and $4.71(\mathrm{CV}=4.93)$ min for starting and black cores, respectively.

A further external white layer was then applied on black cores using commercially available $\mathrm{TiO}_{2-}$ free coating formulations or a standard $\mathrm{TiO}_{2}$-containing one. In the latter case, white-coated reference samples were obtained, which turned out further improved in mechanical resistance with respect to the starting black cores. Moreover, they showed coating thickness of $112.22 \mu \mathrm{m}(\mathrm{CV}=9.23)$ on the top/bottom tablet surfaces and $58.66 \mu \mathrm{m}(\mathrm{CV}=10.07) \mu \mathrm{m}$ on the lateral ones, and were still provided with a dissolution performance $\left(\mathrm{t}_{80 \%}=6.78 \mathrm{~min}, \mathrm{CV}=15.95\right)$ widely within the USP limit criteria for IR tablets $\left(\mathrm{t}_{80 \%}<15 \mathrm{~min}\right)$. Physico-technological characteristics of white-coated tablets are reported in Table 3. Overall, they pointed out reproducible weight and external dimensions, intended as height and diameter. Relevant coating processes were generally proven efficient, leading to products characterized by a different profile of thickness growth as a function of $\mathrm{wg}_{\mathrm{g}}$ (Figure 1).

All the white-coated tablets turned out to be compliant with the dissolution requirement entailing t80\% $<15$ min for IR products. As expected, a relatively slower drug dissolution rate was highlighted during the very first minutes of testing, especially from white-coated tablets with the higher coating thicknesses, which was always greater than that of the reference. On the other hand, some formulations (i.e. AQR, NUT, SPE, VIV) were compliant with the specifications of IR products already after 5 min of testing and even when dealing with the thickest coating (Figure 2). At this time point, except for AQP and SEP, the dissolution from samples with $\mathrm{w}_{\mathrm{g}}$ analogous to that of the standard $\mathrm{TiO}_{2}$-containing formulation turned out faster. 
Table 3: average weight, height, diameter and thickness of the white layer relevant to white-coated tablets.

\begin{tabular}{|c|c|c|c|c|c|c|c|}
\hline \multirow{2}{*}{$\begin{array}{l}\text { Coating } \\
\text { formulation code }\end{array}$} & \multirow{2}{*}{\multicolumn{2}{|c|}{ Parameter }} & \multicolumn{5}{|c|}{ Nominal $w_{g}$ of coated tablets } \\
\hline & & & $1.5 \%$ & $3.0 \%$ & $4.5 \%$ & $6.0 \%$ & $7.5 \%$ \\
\hline \multirow{5}{*}{$\mathbf{A Q P}$} & \multicolumn{2}{|c|}{ Weight, mg (CV) } & $520.62(0.48)$ & $526.83(0.57)$ & $535.34(0.56)$ & $543.29(0.39)$ & $549.12(0.60)$ \\
\hline & \multicolumn{2}{|c|}{ Height, mm (CV) } & $5.61(0.53)$ & $5.68(0.64)$ & $5.70(0.35)$ & $5.77(0.52)$ & $5.85(0.17)$ \\
\hline & \multicolumn{2}{|c|}{ Diameter, mm (CV) } & $11.14(0.11)$ & $11.17(0.18)$ & $11.22(0.27)$ & $11.26(0.29)$ & $11.33(0.18)$ \\
\hline & \multirow{2}{*}{$\begin{array}{l}\text { Thickness, } \mu \mathrm{m} \\
(\mathrm{CV})\end{array}$} & Top/bottom & $62.09(15.48)$ & $82.01(11.74)$ & $134.11(11.49)$ & $169.96(6.97)$ & $203.52(7.10)$ \\
\hline & & Side & $61.19(15.88)$ & $73.14(13.46)$ & $119.00(9.96)$ & $148.49(9.66)$ & $193.94(8.61)$ \\
\hline \multirow{5}{*}{$\mathbf{A Q R}$} & \multicolumn{2}{|c|}{ Weight, mg (CV) } & $519.62(0.35)$ & $525.35(0.53)$ & $534.42(0.67)$ & $543.71(0.40)$ & $550.29(0.89)$ \\
\hline & \multicolumn{2}{|c|}{ Height, mm (CV) } & $5.68(0.53)$ & $5.72(0.35)$ & $5.77(0.69)$ & $5.87(0.34)$ & $5.90(0.33)$ \\
\hline & \multicolumn{2}{|c|}{ Diameter, mm (CV) } & $11.09(0.09)$ & $11.12(0.10)$ & $11.18(0.08)$ & $11.27(0.07)$ & $11.28(0.27)$ \\
\hline & \multirow{2}{*}{$\begin{array}{l}\text { Thickness, } \mu \mathrm{m} \\
(\mathrm{CV})\end{array}$} & Top/bottom & $27.77(22.55)$ & $55.39(15.11)$ & $106.01(12.75)$ & $126.53(8.55)$ & $141.69(8.10)$ \\
\hline & & Side & $24.33(23.48)$ & $51.14(14.87)$ & $92.78(14.43)$ & $110.08(10.59)$ & $123.91(9.33)$ \\
\hline \multirow{5}{*}{ FOR } & \multicolumn{2}{|c|}{ Weight, mg (CV) } & $519.99(0.62)$ & $522.42(0.66)$ & $532.33(0.73)$ & $543.78(0.72)$ & $548.91(0.56)$ \\
\hline & \multicolumn{2}{|c|}{ Height, mm (CV) } & $5.65(0.30)$ & $5.71(0.09)$ & $5.75(0.34)$ & $5.81(0.69)$ & $5.87(0.38)$ \\
\hline & \multicolumn{2}{|c|}{ Diameter, mm (CV) } & $11.08(0.06)$ & $11.12(0.10)$ & $11.15(0.08)$ & $11.19(0.09)$ & $11.30(0.12)$ \\
\hline & \multirow{2}{*}{$\begin{array}{l}\text { Thickness, } \mu \mathrm{m} \\
(\mathrm{CV})\end{array}$} & Top/bottom & $32.47(16.16)$ & $52.33(14.88)$ & $87.35(13.18)$ & $106.71(11.75)$ & $159.29(7.53)$ \\
\hline & & Side & $27.88(20.12)$ & $43.21(13.12)$ & $70.64(14.25)$ & $89.25(13.44)$ & $127.69(10.09)$ \\
\hline \multirow{5}{*}{ INS } & \multicolumn{2}{|c|}{ Weight, mg (CV) } & $520.72(0.33)$ & $522.94(0.48)$ & $533.56(0.67)$ & $545.38(0.88)$ & $553.12(0.81)$ \\
\hline & \multicolumn{2}{|c|}{ Height, mm (CV) } & $5.63(0.36)$ & $5.68(0.54)$ & $5.70(0.70)$ & $5.80(0.69)$ & $5.85(0.34)$ \\
\hline & \multicolumn{2}{|c|}{ Diameter, mm (CV) } & $11.09(0.14)$ & $11.13(0.18)$ & $11.16(0.27)$ & $11.23(0.19)$ & $11.25(0.09)$ \\
\hline & \multirow{2}{*}{$\begin{array}{l}\text { Thickness, } \mu \mathrm{m} \\
\text { (CV) }\end{array}$} & Top/bottom & $48.44(13.52)$ & $69.40(13.27)$ & $109.78(10.11)$ & $158.19(9.48)$ & $191.18(8.38)$ \\
\hline & & Side & $46.41(20.71)$ & $60.26(13.65)$ & $95.69(12.82)$ & $121.16(12.32)$ & $166.53(8.89)$ \\
\hline \multirow{5}{*}{ NUT } & \multicolumn{2}{|c|}{ Weight, $\mathrm{mg}(\mathrm{CV})$} & $516.33(0.68)$ & $528.35(0.51)$ & $534.74(0.43)$ & $542.23(0.78)$ & $552.89(0.52)$ \\
\hline & \multicolumn{2}{|c|}{ Height, mm (CV) } & $5.63(0.35)$ & $5.67(0.36)$ & $5.70(0.70)$ & $5.80(0.69)$ & $5.81(0.32)$ \\
\hline & \multicolumn{2}{|c|}{ Diameter, mm (CV) } & $11.08(0.92)$ & $11.10(0.91)$ & $11.16(0.09)$ & $11.22(0.45)$ & $11.22(0.18)$ \\
\hline & \multirow{2}{*}{$\begin{array}{l}\text { Thickness, } \mu \mathrm{m} \\
\text { (CV) }\end{array}$} & Top/bottom & $40.22(17.51)$ & $50.97(13.76)$ & $96.91(8.80)$ & $115.63(8.52)$ & $127.79(12.73)$ \\
\hline & & Side & $44.53(18.01)$ & $47.56(10.71)$ & $81.55(12.31)$ & $92.68(10.97)$ & $102.82(8.49)$ \\
\hline \multirow{3}{*}{ SEP } & \multicolumn{2}{|c|}{ Weight, mg (CV) } & $518.66(0.77)$ & $529.12(0.53)$ & $533.63(0.69)$ & $539.85(0.59)$ & $529.74(0.57)$ \\
\hline & Height, $\mathrm{mm}(\mathrm{C}$ & & $5.72(0.17)$ & $5.78(0.35)$ & $5.81(0.34)$ & $5.86(0.51)$ & $5.90(0.36)$ \\
\hline & Diameter, $\mathrm{mm}$ & & $11.09(0.09)$ & $11.15(0.08)$ & $11.17(0.07)$ & $11.29(0.27)$ & $11.28(0.26)$ \\
\hline
\end{tabular}




\begin{tabular}{|c|c|c|c|c|c|c|c|}
\hline & \multirow{2}{*}{\begin{tabular}{|l} 
Thickness, $\mu \mathrm{m}$ \\
$(\mathrm{CV})$
\end{tabular}} & Top/bottom & $52.03(23.01)$ & $94.48(17.17)$ & $117.53(16.83)$ & $155.52(16.29)$ & $169.58(12.17)$ \\
\hline & & Side & $54.69(24.30)$ & $80.36(15.49)$ & $74.43(13.99)$ & $124.28(17.53)$ & $135.06(11.73)$ \\
\hline \multirow{5}{*}{ SHE } & \multicolumn{2}{|c|}{ Weight, mg (CV) } & $519.31(0.77)$ & $526.37(0.73)$ & $530.54(0.43)$ & $543.97(0.37)$ & $550.11(0.56)$ \\
\hline & \multicolumn{2}{|c|}{ Height, mm (CV) } & $5.63(0.18)$ & $5.69(0.53)$ & $5.75(0.35)$ & $5.8(0.33)$ & $5.82(0.51)$ \\
\hline & \multicolumn{2}{|c|}{ Diameter, mm (CV) } & $11.10(0.27)$ & $11.13(0.18)$ & $11.24(0.36)$ & $11.22(0.27)$ & $11.29(0.35)$ \\
\hline & \multirow{2}{*}{$\begin{array}{l}\text { Thickness, } \mu \mathrm{m} \\
(\mathrm{CV})\end{array}$} & Top/bottom & $46.92(18.48)$ & $52.94(13.00)$ & $72.09(11.54)$ & $105.16(12.77)$ & $114.19(9.76)$ \\
\hline & & Side & 35.75 (1.89) & $51.34(14.39)$ & $69.48(14.02)$ & $93.01(12.29)$ & $99.55(10.40)$ \\
\hline \multirow{5}{*}{ SPE } & \multicolumn{2}{|c|}{ Weight, mg (CV) } & $519.02(0.23)$ & $530.64(0.51)$ & $531.27(0.60)$ & $542.82(0.57)$ & $546.91(0.79)$ \\
\hline & \multicolumn{2}{|c|}{ Height, mm (CV) } & $5.67(0.05)$ & $5.72(0.08)$ & $5.71(0.10)$ & $5.79(0.08)$ & $5.84(0.07)$ \\
\hline & \multicolumn{2}{|c|}{ Diameter, mm (CV) } & $11.12(0.12)$ & $11.18(0.10)$ & $11.20(0.36)$ & $11.22(0.09)$ & $11.27(0.18)$ \\
\hline & \multirow{2}{*}{$\begin{array}{l}\text { Thickness, } \mu \mathrm{m} \\
(\mathrm{CV})\end{array}$} & Top/bottom & $31.38(21.03)$ & $52.05(18.98)$ & $64.22(14.37)$ & $95.84(18.15)$ & $121.32(12.16)$ \\
\hline & & Side & $28.22(28.88)$ & 47.69 (19.94) & $58.44(16.29)$ & $80.12(11.52)$ & $100.68(12.53)$ \\
\hline \multirow{5}{*}{ VIV } & \multicolumn{2}{|c|}{ Weight, mg (CV) } & $519.01(0.37)$ & $523.88(0.31)$ & $531.13(0.87)$ & $544.94(0.37)$ & $549.62(0.71)$ \\
\hline & \multicolumn{2}{|c|}{ Height, mm (CV) } & $5.61(0.18)$ & $5.63(0.35)$ & $5.72(0.35)$ & $5.76(0.34)$ & $5.81(0.33)$ \\
\hline & \multicolumn{2}{|c|}{ Diameter, mm (CV) } & $11.06(0.09)$ & $11.08(0.08)$ & $11.16(0.18)$ & $11.15(0.18)$ & $11.21(0.17)$ \\
\hline & \multirow{2}{*}{$\begin{array}{l}\text { Thickness, } \mu \mathrm{m} \\
(\mathrm{CV})\end{array}$} & Top/bottom & $40.36(22.86)$ & $53.78(17.61)$ & $75.53(14.99)$ & $115.42(10.34)$ & $129.59(12.89)$ \\
\hline & & Side & $30.65(20.48)$ & $41.15(14.34)$ & $60.20(17.43)$ & $97.39(11.14)$ & $106.80(9.91)$ \\
\hline
\end{tabular}



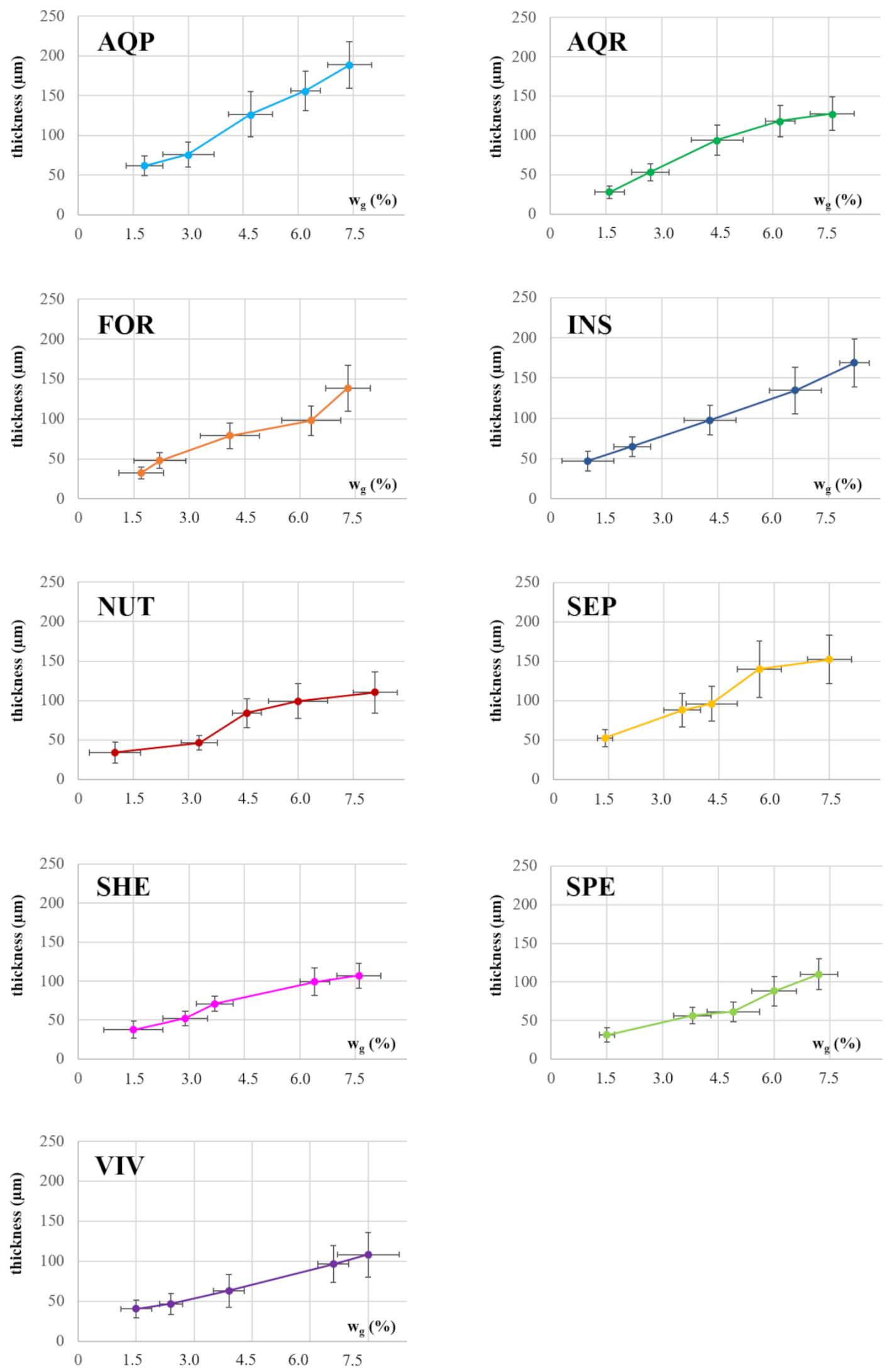

Figure 1: $\mathrm{wg}$ versus coating thickness profiles relevant to white-coated tablets (mean values of coating thickness measured on top/bottom and lateral surfaces of tablets were considered); the coating formulation code is reported in each figure panel. 


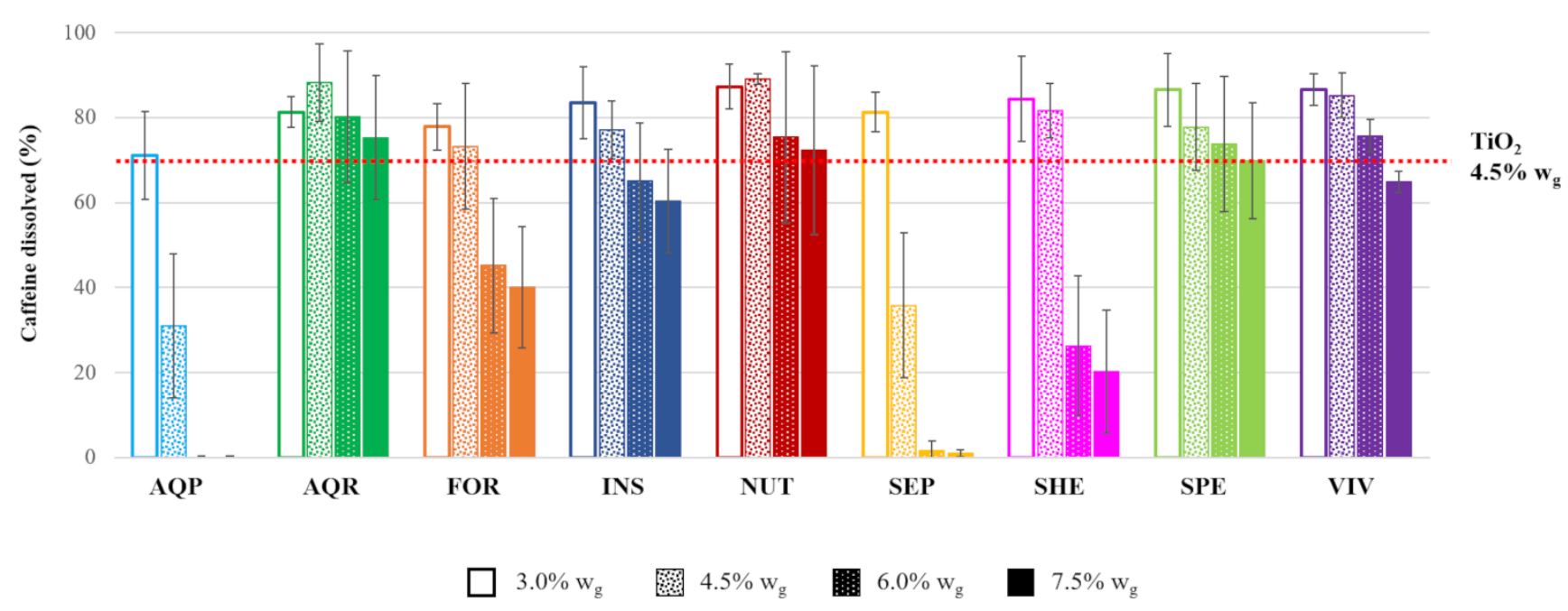

Figure 2: amount of drug dissolved after 5 min of testing from white-coated tablets (the amount of caffeine dissolved from the white-coated reference is indicated by the red dotted line)

\subsection{Evaluation of the coating color}

\subsubsection{Human eyes perception}

Two different panels were purposely developed for the simultaneous evaluation of the color of all the white-coated tablets comparing them between each other (test 1) or with the reference in the case of tablets coated up to 4.5 and $7.0 \% \mathrm{wg}_{\mathrm{g}}$ (test 2). Overall results collected from 20 volunteers are summarized in Table 4 and Figure 3.

Table 4: average scores (CV) of the test panel 1 relevant to white-coated tablets

\begin{tabular}{|c|c|c|c|c|c|}
\hline \multirow{2}{*}{$\begin{array}{l}\text { Coating } \\
\text { formulation code }\end{array}$} & \multicolumn{5}{|c|}{ Nominal wg of coated tablets } \\
\hline & $\mathbf{1 . 5 \%}$ & $\mathbf{3 . 0 \%}$ & $\mathbf{4 . 5 \%}$ & $\mathbf{6 . 0 \%}$ & $\mathbf{7 . 5 \%}$ \\
\hline AQR & $5.3(26.3)$ & $5.6(29.8)$ & $6.9(22.6)$ & $7.5(17.3)$ & $6.3(38.6)$ \\
\hline AQP & $10.0(0.0)$ & $9.6(9.5)$ & $9.0(15.5)$ & $9.2(13.6)$ & $8.9(18.1)$ \\
\hline FOR & $1.4(43.9)$ & $2.4(34.7)$ & $3.0(24.3)$ & $2.6(34.8)$ & $4.2(51.1)$ \\
\hline INS & $5.6(29.1)$ & $5.1(27.7)$ & $4.9(24.7)$ & $5.8(26.9)$ & $5.5(37.4)$ \\
\hline NUT & $8.4(10.9)$ & $8.3(14.85)$ & $8.2(18.4)$ & $7.3(25.5)$ & $6.6(401.0)$ \\
\hline SEP & $3.6(21.7)$ & $2.2(51.2)$ & $2.3(40.3)$ & $2.1(56.2)$ & $4.1(59.8)$ \\
\hline SHE & $7.3(13.2)$ & $8.2(11.9)$ & $7.7(18.9)$ & $7.6(25.1)$ & $7.8(19.8)$ \\
\hline SPE & $2.2(53.8)$ & $2.4(45.7)$ & $1.5(43.9)$ & $2.2(38.9)$ & $1.6(47.3)$ \\
\hline VIV & $6.1(24.7)$ & $6.3(18.42)$ & $6.5(25.0)$ & $5.9(278.0)$ & $5.1(42.5)$ \\
\hline
\end{tabular}



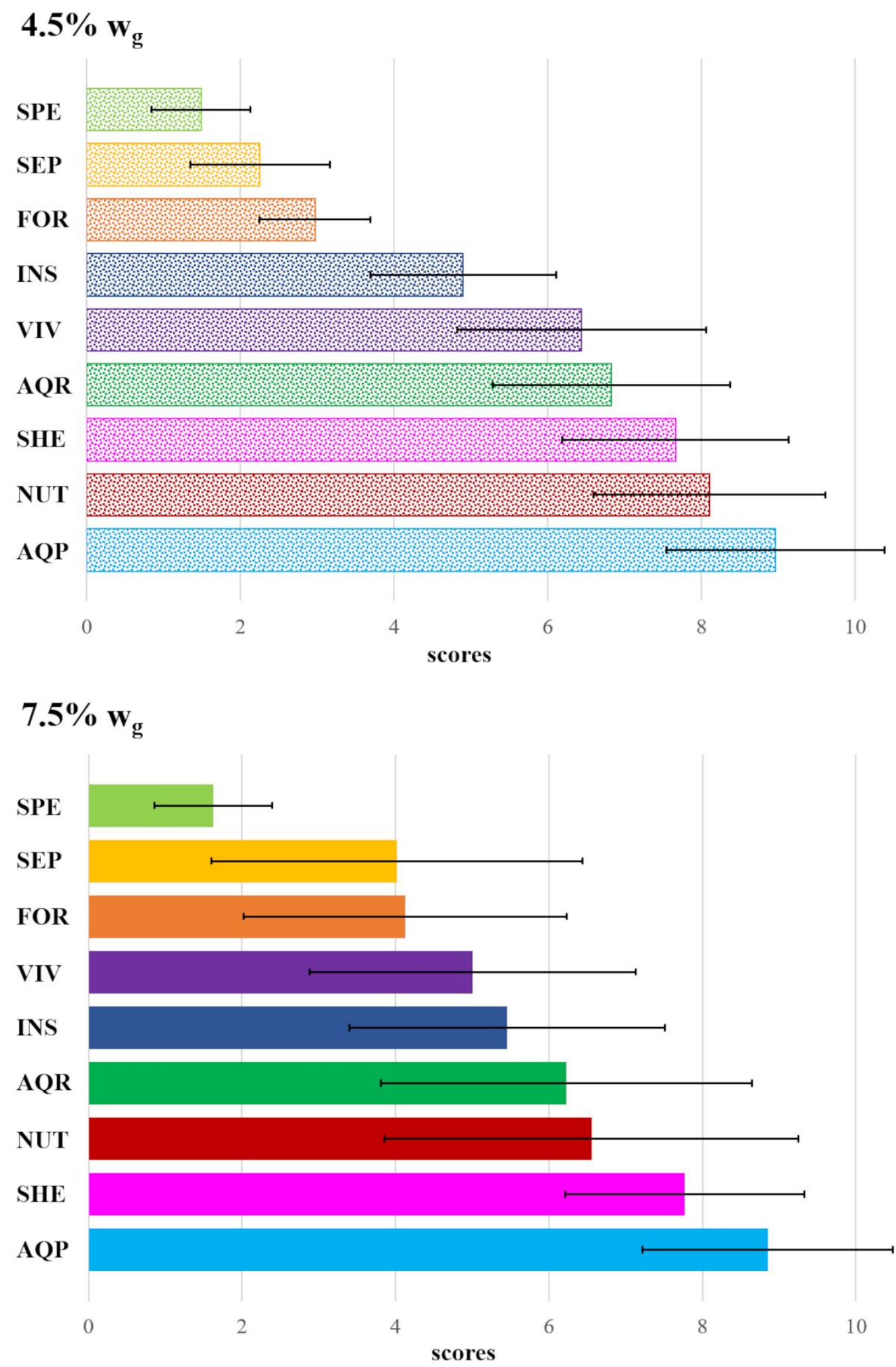

Figure 3: results of the test panel 2 relevant to white-coated tablets with 4.5 and $7.5 \% \mathrm{wg}_{\mathrm{g}}$ compared to the reference. 
The data collected from volunteers were useful to identify the $\mathrm{TiO}_{2}$-free coating formulations always ranked in the first 3 positions (i.e. AQP, NUT and SHE) or in the last 3 ones (i.e. SPE, FOR and SEP). The higher the position in the ranking, the whiter the color of the coated tablets was perceived and the more similar to that of the white-coated reference for test 2 in particular. Limiting to the results of $7.5 \% \mathrm{wg}$, also the AQR formulation turned out among the best ones. Indeed, it would be important to verify whether the different ranking highlighted by the volunteers corresponded to real color differences or was falsely induced by the need for ordering the observed samples.

\subsubsection{D color space analysis}

The need for distinguish and classifying different colors, assessing them quantitatively, is well recognized in numerous fields, from agriculture to food industry and dentistry (Jin et al., 2007; Sánchez-Marañón et al., 1997; Weatherall et al., 1991,1999). So far, the CIELab space is already used in many industrial applications (e.g. paint industry) for the identification of an effective white index (Jung et al., 2013; Luo et al., 2009; Pérez et al., 2016). CIELab, also referred to as L*a*b*, is a 3D color space proposed by the International Commission on Illumination in 1976 and defined by the three axes $\mathrm{L}^{*}, \mathrm{a}^{*}$ and $\mathrm{b}^{*}$, each letter representing a quantitative measurement of lightness, rednessgreenness and blueness-yellowness, respectively (Figure 4a) (Gulrajani 2010; Hunt et al., 2011; Sharma G., 2003). Indeed, CIELab color space was designed to graphically represent all the possible colors detected by the human eye, thus enabling a more efficient communication of color perceptions and relevant differences. It was based on the opponent color model, for which red/green and blue/yellow form opponent pairs. According to this theory, an object cannot be green and red or blue and yellow at the same time. When measuring absolute values, the $\mathrm{a}^{*}$ axis refers to the green-red opponent colors, with negative values toward green and positive values toward red; on the other hand, the $b^{*}$ axis represents the blue-yellow opponents, with negative numbers toward blue and positive ones toward yellow (Figure 4b). Finally, the $\mathrm{L}^{*}$ value of 0 identifies the ideal absolute black, while 100 refers to the ideal absolute white color. Within this 3D space, an extremely reliable identification 
of colors can be assessed, as any color correspond to a unique vector starting from the origin of the Cartesian axes, i.e. a point into this space defined by the three $\mathrm{L}^{*}, \mathrm{a}^{*}$ and $\mathrm{b}^{*}$ coordinates. Notably, the center is achromatic and going away from it - by increasing the absolute value of $a^{*}$ and $b^{*}$ as well by moving along the $\mathrm{L}^{*}$ axis from 0 to 100 , in other words from black to white across all the achromatic grey levels - the color saturation increases. Besides allowing the identification of diverse colors with objective parameters, CIELab also enables the quantification of color differences (Figure 4c). In fact, starting from the specific coordinates of two color samples (i.e. $\mathrm{L}^{*}{ }_{1}, \mathrm{a}^{*}{ }_{1}, \mathrm{~b}^{*}{ }_{1}$ and $\mathrm{L}^{*}{ }_{2}$, $\mathrm{a}^{*}, \mathrm{~b}^{*}$ ), it is possible to calculate the differences from the absolute values for each axis (i.e. $\Delta \mathrm{L}^{*}$, $\left.\Delta \mathrm{a}^{*}, \Delta \mathrm{b}^{*}\right)$. In addition, the overall difference between two colors was quantified through the identification of the CIE color difference $1976\left(\Delta \mathrm{E}^{*} \mathrm{ab}\right)$, which represents the euclidean distance between the two points in the space considered. Because human eyes first perceive changes in hue, then those in clarity and finally modifications in chroma, the CIELab space turned out to be not as perceptually efficient as desired, especially in the saturated regions (Choudhury 2014; Gulrajani 2010). Therefore, its cartesian axes were replaced by polar coordinates (i.e. CIELCh coordinates) (Figure 4d). The position of a point was thus described by a vector and by an angle, named chroma $\left(\mathrm{C}^{*}\right)$ and hue $\left(\mathrm{h}^{\circ}\right)$, respectively. $\mathrm{C}^{*}$, which measures saturation or purity of a color, is equal to 0 in the center and increases moving away from it as well as along the $\mathrm{a}^{*}-\mathrm{b}^{*}$ plane. On the other hand, $\mathrm{h}^{\circ}$ starts on the $+a^{*}$ axis, having the $0^{\circ}$ value corresponding to $+a^{*}$ (red), $90^{\circ}$ to $+b^{*}$ (yellow), $180^{\circ}$ to $a^{*}$ (green) and $270^{\circ}$ to $-b^{*}$ (blue). L* still remained a measurement of the lightness as in the CIELab space. 

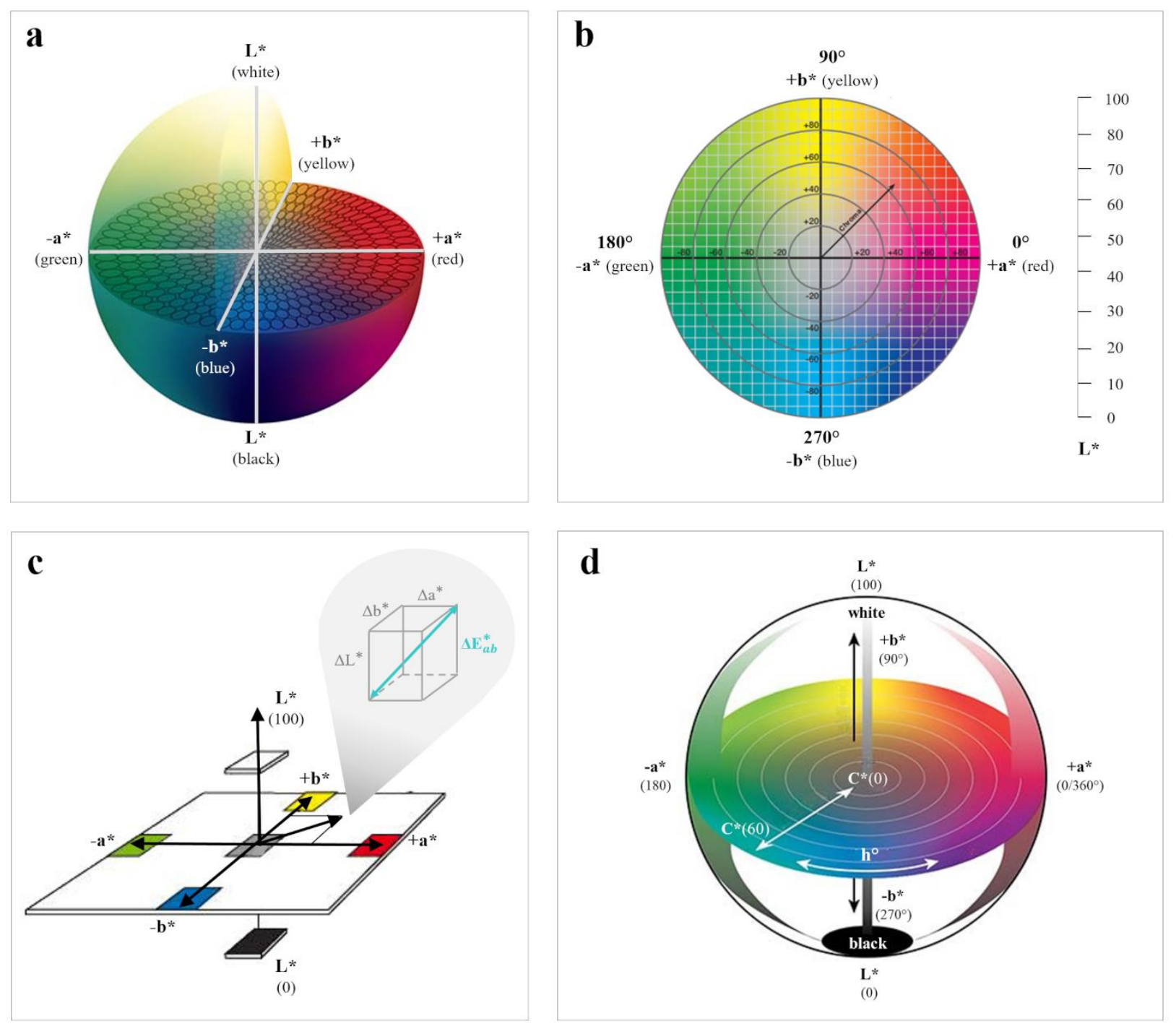

Figure 4: outlines of (a) the CIELab 3D space and relevant cartesian coordinates, (b) a horizontal section of the latter in which $\mathrm{L}^{*}$ value is equal to 50 , (c) the relevant method to calculate $\Delta \mathrm{E}^{*}{ }_{\mathrm{ab}}(\mathrm{d})$ the CIELab 3D space and relevant CIELCh parameters.

The 3D color space was further improved by adding compensation factors, particularly for $\mathrm{L}^{*}, \mathrm{C}^{*}$ and $\mathrm{h}^{\circ}$, and a new equation was proposed in 2000 leading to the definition of a $\Delta \mathrm{E}^{*} 00$ parameter to enhance the identification of color differences.

In Table 5 cartesian and polar parameters relevant to white-coated tablets and $\mathrm{TiO}_{2}$-containing reference are reported. 
Table 5: CIELab and CIELCh parameters relevant to tablets coated with the reference $\mathrm{TiO}_{2}$-containing formulation and the commercial $\mathrm{TiO}$-free coating ones.

\begin{tabular}{|c|c|c|c|c|c|c|}
\hline \multirow{2}{*}{$\begin{array}{l}\text { Coating } \\
\text { formulation } \\
\text { code }\end{array}$} & \multirow{2}{*}{ Parameter } & \multicolumn{5}{|c|}{ Nominal $\mathrm{wg}_{\mathrm{g}}$ of coated tablets } \\
\hline & & $1.5 \%$ & $3.0 \%$ & $4.5 \%$ & $6.0 \%$ & $7.5 \%$ \\
\hline \multirow{5}{*}{$\mathrm{TiO}_{2}$} & $\mathrm{~L}^{*}(\mathrm{CV})$ & & & $96.24(0.28)$ & & \\
\hline & $a^{*}(\mathrm{CV})$ & & & $-0.62(4.08)$ & & \\
\hline & $\mathrm{b}^{*}(\mathrm{CV})$ & & & $0.49(42.87)$ & & \\
\hline & $\mathrm{C}^{*}(\mathrm{CV})$ & & & $0.81(11.22)$ & & \\
\hline & $\mathrm{h}^{\circ}(\mathrm{CV})$ & & & $147.28(9.30)$ & & \\
\hline \multirow{5}{*}{ AQP } & $\mathrm{L}^{*}(\mathrm{CV})$ & $84.44(4.09)$ & $89.67(1.24)$ & $93.09(0.73)$ & $94.32(0.84)$ & $95.58(0.36)$ \\
\hline & $\mathrm{a}^{*}(\mathrm{CV})$ & $-0.61(14.32)$ & $-0.49(6.82)$ & $-0.41(4.93)$ & $-0.38(4.75)$ & $-0.34(6.44)$ \\
\hline & $\mathrm{b}^{*}(\mathrm{CV})$ & $-2.18(21.82)$ & $-1.43(14.27)$ & $-0.78(18.74)$ & $-0.50(33.51)$ & $-0.21(41.52)$ \\
\hline & $\mathrm{C}^{*}(\mathrm{CV})$ & $2.26(21.22)$ & $1.52(13.32)$ & $0.88(15.52)$ & $0.63(23.36)$ & $0.41(12.71)$ \\
\hline & $\mathrm{h}^{\circ}(\mathrm{CV})$ & $246.94(0.75)$ & $242.38(0.96)$ & $231.24(1.73)$ & $220.08(3.15)$ & $201.61(3.96)$ \\
\hline \multirow{5}{*}{ AQR } & $\mathrm{L}^{*}(\mathrm{CV})$ & $82.43(2.57)$ & $88.59(1.68)$ & $93.24(0.95)$ & $95.03(0.50)$ & $95.68(0.29)$ \\
\hline & $\mathrm{a}^{*}(\mathrm{CV})$ & $-1.40(6.01)$ & $-1.05(8.75)$ & $-0.83(4.60)$ & $-0.76(3.12)$ & $-0.73(3.31)$ \\
\hline & $\mathrm{b}^{*}(\mathrm{CV})$ & $-4.12(10.39)$ & $-2.38(16.72)$ & $-0.81(43.55)$ & $0.15(157.89)$ & $0.45(31.68)$ \\
\hline & $\mathrm{C}^{*}(\mathrm{CV})$ & $4.35(9.83)$ & $2.60(15.34)$ & $1.18(21.44)$ & $0.80(7.65)$ & $0.87(8.84)$ \\
\hline & $\mathrm{h}^{\circ}(\mathrm{CV})$ & $242.93(0.64)$ & $236.08(0.98)$ & $221.40(5.18)$ & $172.89(6.39)$ & $158.16(3.99)$ \\
\hline \multirow{5}{*}{ FOR } & $\mathrm{L}^{*}(\mathrm{CV})$ & $68.67(7.44)$ & $78.19(4.60)$ & $86.14(1.53)$ & $87.73(1.78)$ & $92.41(0.66)$ \\
\hline & $a^{*}(\mathrm{CV})$ & $-1.34(13.36)$ & $-1.30(4.30)$ & $-1.15(3.13)$ & $-1.12(4.12)$ & $-1.02(2.86)$ \\
\hline & $\mathrm{b}^{*}(\mathrm{CV})$ & $-7.10(4.69)$ & $-5.74(8.49)$ & \begin{tabular}{|l}
$-4.02(5.90)$ \\
\end{tabular} & $-3.67(10.41)$ & $-2.15(10.25)$ \\
\hline & $\mathrm{C}^{*}(\mathrm{CV})$ & $7.23(4.72)$ & $5.88(8.04)$ & $4.18(5.51)$ & $3.83(9.71)$ & $2.39(7.87)$ \\
\hline & $\mathrm{h}^{\circ}(\mathrm{CV})$ & $254.29(0.74)$ & $251.16(0.71)$ & $246.77(0.51)$ & $245.34(0.79)$ & $234.27(1.51)$ \\
\hline \multirow{5}{*}{ INS } & $\mathrm{L}^{*}(\mathrm{CV})$ & $75.76(2.59)$ & $80.97(2.44)$ & $86.15(2.05)$ & $90.56(0.78)$ & $91.45(0.57)$ \\
\hline & $a^{*}(\mathrm{CV})$ & $-0.65(6.35)$ & $-0.59(8.36)$ & $-0.53(5.70)$ & $-0.45(6.25)$ & $-0.43(4.27)$ \\
\hline & $\mathrm{b}^{*}(\mathrm{CV})$ & $-2.22(11.39)$ & $-1.55(22.23)$ & $-0.62(59.90)$ & $0.44(58.14)$ & $0.73(29.97)$ \\
\hline & $\mathrm{C}^{*}(\mathrm{CV})$ & $2.31(10.88)$ & $1.66(20.11)$ & $0.84(36.68)$ & $0.66(26.92)$ & $0.86(20.45)$ \\
\hline & $\mathrm{h}^{\circ}(\mathrm{CV})$ & $246.10(0.69)$ & $239.59(1.89)$ & $214.82(6.27)$ & $148.90(9.97)$ & $132.91(7.71)$ \\
\hline
\end{tabular}




\begin{tabular}{|c|c|c|c|c|c|c|}
\hline \multirow{5}{*}{ NUT } & $\mathrm{L}^{*}(\mathrm{CV})$ & $76.94(2.85)$ & $84.64(2.00)$ & $90.42(0.87)$ & $92.03(0.66)$ & $92.77(0.55)$ \\
\hline & $\mathrm{a}^{*}(\mathrm{CV})$ & $-0.75(4.19)$ & $-0.76(5.74)$ & $-0.87(7.57)$ & $-1.02(5.00)$ & $-1.01(5.96)$ \\
\hline & $\mathrm{b}^{*}(\mathrm{CV})$ & $-1.52(19.34)$ & $-0.26(152.65)$ & $2.12(23.95)$ & $2.86(13.81)$ & $3.32(14.23)$ \\
\hline & C* $(\mathrm{CV})$ & $1.70(15.58)$ & $0.89(15.33)$ & \begin{tabular}{|l|}
$2.30(21.29)$ \\
\end{tabular} & $3.04(12.55)$ & $3.48(13.44)$ \\
\hline & $\mathrm{h}^{\circ}(\mathrm{CV})$ & $232.97(2.41)$ & $191.96(9.36)$ & $122.52(4.11)$ & $118.44(2.63)$ & $114.82(1.88)$ \\
\hline \multirow{5}{*}{ SEP } & $\mathrm{L}^{*}(\mathrm{CV})$ & $62.05(4.22)$ & $70.76(2.95)$ & $69.59(2.48)$ & $78.68(1.92)$ & $84.31(0.99)$ \\
\hline & $\mathrm{a}^{*}(\mathrm{CV})$ & $-0.51(9.82)$ & $-0.53(7.71)$ & $-0.53(8.85)$ & $-0.56(7.01)$ & $-0.61(6.46)$ \\
\hline & $\mathrm{b}^{*}(\mathrm{CV})$ & $-2.13(10.41)$ & $-1.51(19.34)$ & $-1.18(12.94)$ & $-0.27(69.93)$ & $-0.06(241.58)$ \\
\hline & $\mathrm{C}^{*}(\mathrm{CV})$ & $2.19(10.10)$ & $1.60(16.87)$ & $1.29(10.51)$ & 0.65 (10.99) & $0.62(9.06)$ \\
\hline & $\mathrm{h}^{\circ}(\mathrm{CV})$ & $250.07(0.78)$ & $241.46(2.42)$ & $235.74(1.94)$ & $197.41(5.98)$ & $183.78(9.06)$ \\
\hline \multirow{5}{*}{ SHE } & $\mathrm{L}^{*}(\mathrm{CV})$ & $80.76(3.37)$ & $86.66(1.26)$ & $91.20(0.61)$ & $92.49(0.74)$ & $94.02(0.34)$ \\
\hline & $\mathrm{a}^{*}(\mathrm{CV})$ & $-1.24(5.84)$ & $-1.01(5.98)$ & $-0.78(3.35)$ & $-0.70(6.18)$ & $-0.64(5.03)$ \\
\hline & $\mathrm{b}^{*}(\mathrm{CV})$ & $-4.11(9.16)$ & $-2.91(9.32)$ & $-1.65(13.31)$ & $-1.18(20.46)$ & $-0.66(21.40)$ \\
\hline & $\mathrm{C}^{*}(\mathrm{CV})$ & $4.29(8.81)$ & $3.07(8.91)$ & $1.83(11.07)$ & $1.38(16.64)$ & $0.92(12.65)$ \\
\hline & $\mathrm{h}^{\circ}(\mathrm{CV})$ & $245.57(0.44)$ & $242.49(0.44)$ & $234.29(1.54)$ & $227.96(1.84)$ & $214.39(2.37)$ \\
\hline \multirow{5}{*}{ SPE } & $\mathrm{L}^{*}(\mathrm{CV})$ & $66.86(4.66)$ & $75.93(2.34)$ & $81.48(1.71)$ & $86.43(1.24)$ & $88.69(0.71)$ \\
\hline & $a^{*}(\mathrm{CV})$ & $-1.34(9.18)$ & $-1.34(4.06)$ & $-1.24(3.86)$ & $-1.07(3.76)$ & $-1.00(3.55)$ \\
\hline & $\mathrm{b}^{*}(\mathrm{CV})$ & $-6.53(6.07)$ & $-5.41(5.10)$ & $-4.51(5.80)$ & $-3.16(9.33)$ & $-2.46(8.38)$ \\
\hline & $\mathrm{C}^{*}(\mathrm{CV})$ & $6.67(5.97)$ & $5.58(4.87)$ & $4.68(5.58)$ & $3.34(8.69)$ & $2.66(7.50)$ \\
\hline & $\mathrm{h}^{\circ}(\mathrm{CV})$ & $252.91(0.56)$ & $249.67(0.41)$ & $247.53(0.36)$ & $242.90(0.62)$ & $238.63(0.73)$ \\
\hline \multirow{5}{*}{ VIV } & $\mathrm{L}^{*}(\mathrm{CV})$ & $76.84(2.45)$ & $81.92(2.10)$ & $88.56(0.90)$ & $89.54(0.77)$ & $91.59(0.59)$ \\
\hline & $\mathrm{a}^{*}(\mathrm{CV})$ & $-1.35(2.42)$ & $-1.28(3.77)$ & $-1.13(2.23)$ & $-1.11(2.71)$ & $-1.07(3.49)$ \\
\hline & $\mathrm{b}^{*}(\mathrm{CV})$ & $-3.87(10.29)$ & $-2.82(15.06)$ & $-0.91(35.04)$ & $-0.60(43.50)$ & $0.18(153.20)$ \\
\hline & $\mathrm{C}^{*}(\mathrm{CV})$ & $4.10(9.32)$ & $3.10(13.08)$ & \begin{tabular}{|l|}
$1.47(13.04)$ \\
\end{tabular} & $1.28(7.88)$ & $1.12(5.67)$ \\
\hline & $\mathrm{h}^{\circ}(\mathrm{CV})$ & $242.14(0.89)$ & $235.52(1.31)$ & $207.70(4.11)$ & $199.64(4.21)$ & $173.63(5.59)$ \\
\hline
\end{tabular}


Focusing on the data relevant to the white-coated reference, it turned out not perfectly pure and achromatic, as highlighted from $\mathrm{a}^{*}$ and $\mathrm{b}^{*}$ measurements, which showed a slightly greenish and yellowish tendency. However, the very high lightness of the coating ( $\mathrm{L}^{*}$ over 96 ) was correlated to its high opacifying capacity, white color and covering ability (Figure 5). At the same $\mathrm{wg}_{\mathrm{g}}$ of $4.5 \%$, all $\mathrm{TiO}_{2}$-free coating formulations tested showed a high $\mathrm{L}$ value (i.e. in the 70-93 range), but always lower than that of the reference. This can also explain the fact that slightly different white colors are visually perceived for such coatings by the volunteers interviewed. Indeed, at lower values of L, both color flame and saturation become relatively more important. However, only at the highest coating thickness the influence of the black color of the cores can be considered negligible, and the actual coating characteristics would become assessable.

Overall, although the tools for a more in-depth analysis of the actual color characteristics of the coated tablets were available, the choice of the white color for the coating and the use of black cores underneath, on which to evaluate the covering properties of the various formulations tested, make further assessment of little relevance and interest. In this respect, in the evaluation of the $\mathrm{TiO}_{2}$-free coating formulations, the following features appeared of major interest: the ability to cover the black surface of the cores and the difference in color of white-coated tablets with respect to the reference. Based on the objective of the work, we started from evaluating the last parameter, i.e. by calculating the $\Delta \mathrm{E}^{*}{ }_{00}$ parameter (Figure 6). 

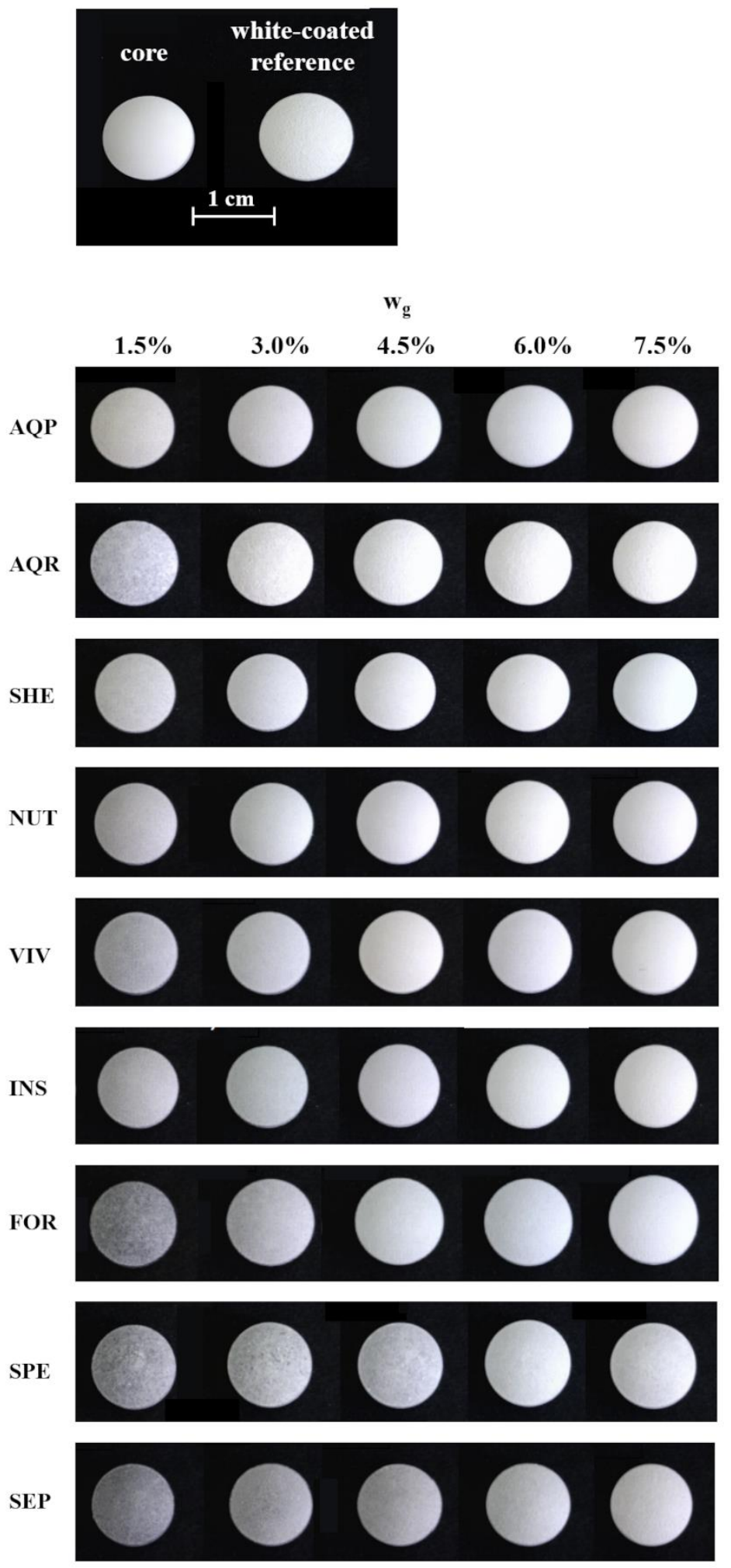

Figure 5: photographs of a white core compared with the white-coated reference and all the whitecoated tablets with different $\mathrm{wg}$ 

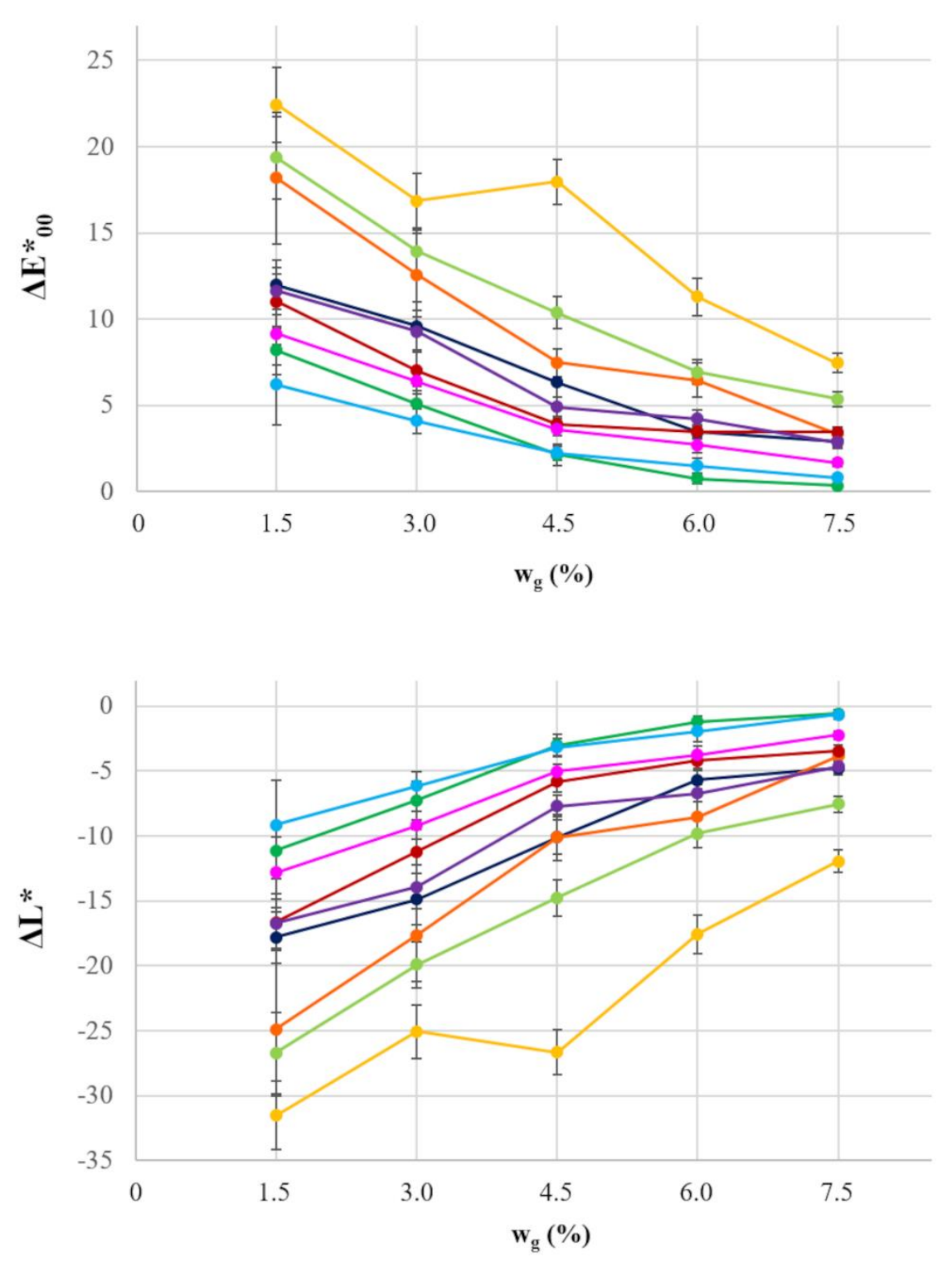

NUT

Figure 6: (a) $\Delta \mathrm{L}^{*}$ and (b) $\Delta \mathrm{E}^{*}{ }_{00}$ values calculated with respect to the reference, relevant to whitecoated tablets with different $\mathrm{wg}$

As expected, chromatic differences between white-coated tablets and the reference decreased when increasing the amount of coating applied. The lower the $\Delta \mathrm{E}^{*}{ }_{00}$ value, the more difficult is for the human eye to perceive the color difference between two samples. However, the acceptable perception limit highly depends on the field of application and also on the extent and nature of the colored surfaces being compared. Although $\Delta \mathrm{E}^{*} 00$ equal to 1 can be identified as a sort of target in various industrial fields (e.g. automotive, fashion) to consider two products basically of the same color, in our specific application $\Delta \mathrm{E}^{*}{ }_{00}$ values $<5$ turned out to indicate differences generally not perceived 
during visual observation of the white-coated tablets and the white reference. In this respect, SPEand SEP-coated tablets turned out different from the reference, regardless of the $\mathrm{w}_{\mathrm{g}}$, while the FORcoated ones showed the same result with the sole exception of the maximum $\mathrm{wg}_{\mathrm{g}}$. On the contrary, tablets coated with AQR and AQP formulations were no longer distinguishable from the reference already starting from $\mathrm{wg}_{\mathrm{g}}$ equal to $3.0 \%$. Moreover, as expected based on the use of black cores, a correspondence between $\Delta \mathrm{E}^{*} 00$ and $\Delta \mathrm{L}^{*}$ values could be ruled out. In fact, the rank related to overall color differences was comparable to that generated by the differences in lightness. This can be explained by the fact that very low shift from 0 value for the $a^{*}$ and $b^{*}$ parameters were generally observed with all the white-coated samples as well as the white reference. Overall, $\Delta \mathrm{E}^{*} 00$ and $\Delta \mathrm{L}^{*}$ parameters turned out to be significantly different $(\mathrm{p}<0.05)$. Therefore, white-coated tablets with lower $\mathrm{w}_{\mathrm{g}}$ turned out useful to determine the ranking of formulations in terms of ability to cover the surface of the black cores underneath. Indeed, this ranking was found very similar to that obtained based on human eyes perception.

As the $b^{*}$ values measured for $1.5 \% \mathrm{wg}_{\mathrm{g}}$ coated-tablets generally highlighted the presence of a yellowblue flame with a tendency towards blue, it was confirmed that the black color of the underlying coating was still predominant. Moreover, as the $\Delta \mathrm{L}^{*}$ increased, other chromatic characteristics, including saturation and purity of the color (i.e. $\left.\mathrm{C}^{*}\right)$, may become further important as for INS, VIV, FOR and NUT samples.

Finally, returning to the peculiar chromatic features of each $\mathrm{TiO}_{2}$-free coating formulation, whitecoated tablets with $7.5 \% \mathrm{wg}$ can be used to deepen the color evaluation (Table 5). By way of example, we considered those formulations which generally showed major or minor color differences with respect to the $\mathrm{TiO}_{2}$-containing reference. SEP-coated tablets were characterized by a greenish tendency, as already observed for the reference. Moreover, they resulted completely achromatic with respect to the blue and yellow colors. However, SEP-coated tablets exhibited lower $\mathrm{L}^{*}$ and $\mathrm{C}^{*}$ with respect to the reference, and probably for this reason they were penalized in the comparison. Also the SPE-coated tablets showed a tendency towards green, which resulted higher than that observed with 
SEP and with the reference. Besides the low lightness, the $b^{*}$ data pointed out a marked blue component of the color, which was on the opposite side of the color space with respect to that sought. SEP-coated samples were therefore characterized by a major chromatic difference with respect to the reference. A lower greenish tendency - approximately half of that of the reference - coupled with a slight bluish one were the main chromatic features of the AQP formulation. In this respect, AQP could be considered the purest film-forming formulation, even taking into account the $\mathrm{TiO}_{2}$-based coating. The high $\mathrm{L}^{*}$ value registered also contributed to reduce the perceived difference when comparing AQP-coated tablets with the reference ones. The $\mathrm{C}^{*}$ values - half of the $\mathrm{TiO}_{2}$-containing formulation - pointed out quite low chromatic characteristics of AQP and therefore its high purity. On the other hand, the green and yellow tendency of AQR were particularly close to that of the reference standard so as minimal chromatic difference could be ruled out with respect to white-coated reference, as confirmed by $\mathrm{C}^{*}$. In addition, $\mathrm{AQR}$ was the formulation characterized by the lowest differences in terms of $\Delta \mathrm{L}^{*}$ with respect to the reference.

\section{Conclusions}

The work performed was mainly aimed at identifying suitable alternatives to $\mathrm{TiO}_{2}$ as an opacifier in coating formulations able to provide a non-transparent white layer onto solid substrates. In this respect, a variety of $\mathrm{TiO}_{2}$-free $\mathrm{R} 2 \mathrm{U}$ cosmetic coating formulations were considered. These showed, when applied up to technically sustainable $\mathrm{wg}$, good covering capability, giving raise to coated tablets with good technological/dissolution properties together with the attainment of a pleasant white from the user's perspective, more or less similar to that of $\mathrm{TiO}_{2}$-containing reference. In view of the data collected, all the cosmetic coating formulations investigated turned out to represent promising alternatives to those containing $\mathrm{TiO}_{2}$, especially considering that all the white-coated tablets, even at the highest $\mathrm{wg}_{\mathrm{g}}$, fulfilled the dissolution requirements for IR products. Therefore, the selection of the final formulation could be performed having a relatively wide range of possibilities and based on the 
user/clients preference towards white colors with more pronounced yellow, green, blue or red flames. Indeed, a thorough assessment of coloring as well as of covering performance of the coatings under investigation was performed by means of an objective and quantitative method based on the spectrophotometric assessment of the CIELab and CIELCh parameters. It was demonstrated that the color ranking highlighted by the visual observation of volunteers corresponded to real color differences of the white-coated samples and was not falsely induced by the need for rating comparatively the observed samples. In this respect, the use of analytical tools for quality assessment would be pivotal for coating processes that may require industrial validation, for coated products that may have to meet well-defined reproducibility requirements and for color matching purposes.

The same strategy here pursued could also be employed in the development of colored products to support and speed up relevant formulation stages. The method developed in this work could become routine in companies focused on coating processes, especially in the case of color matching required by the clients or when the customers target the achievement of a very peculiar color for their products.

\section{References}

Bettini S., Boutet-Robinet E., Cartier C., Coméra C., Gaultier E., Dupuy J., Naud N., Taché S., Grysan P., Reguer S., Thieriet N., Réfrégiers M., Thiaudière D., Cravedi J. P., Carrière M., Audinot J. N., Pierre F. H., Guzylack-Piriou L., Houdeau E., 2017, Food-grade $\mathrm{TiO}_{2}$ impairs intestinal and systemic immune homeostasis, initiates preneoplastic lesions and promotes aberrant crypt development in the rat colon, Sci. Rep., 7: 40373.

Choudhury A.S.R., 2014, Principles of color appearance and measurements Volume 1, Woodhead publishing, Cambrigde UK.

Cole, G., Hogan, J., Aulton, M., 1995, Pharmaceutical Coating Technology, Taylor \& Frencis Ed., CBC Press, London, UK. 
Dunford, R., Salinaro, A., Cai, L., Serpone, N., Horikoshi, S., Hidaka, H., \& Knowland, J., 1997, Chemical oxidation and DNA damage catalysed by inorganic sunscreen ingredients. FEBS Letters, 418: 87-90.

Felton L.A., McGinity J.W., 2002, Influence of insoluble excipients on film coating systems, Drug Dev. Ind. Pharm. 28: 225-243.

Felton L.A., Porter S.C., 2013, An update on pharmaceutical film coating for drug delivery, Expert Opin. Drug Deliv., 10: 421-435.

Gulrajani M.L. Ed., 2010, Color measurements - Principles, advances and industrial applications, Woodhead Publishing, Oxford, UK

Gurr J. R., Wang A. S. S., Chen C. H., Jan K. Y., 2005, Ultrafine titanium dioxide particles in the absence of photoactivation can induce oxidative damage to human bronchial epithelial cells, Toxicology, 213: 66-73.

https://apps.fas.usda.gov/newgainapi/api/report/downloadreportbyfilename?filename=France\%20ba ns\%20Titanium\%20Dioxide\%20in\%20food\%20products\%20by\%20January\%202020_Paris_Franc e_5-3-2019.pdf, last access on January 5, 2022

https://www.anses.fr/en/system/files/ERCA2019SA0036.pdf, last Access on November 18, 2021 https://www.efsa.europa.eu/en/news/titanium-dioxide-e171-no-longer-considered-safe-when-usedfood-additive, last access on January 5, 2022 https://nutraceuticalbusinessreview.com/news/article_page/Manufacturing_pressure_accelerates_m ove_to_fully_formulated_film_coatings/169691, last access on January 5, 2022

Hunt R.W.G., Pointer M.R., 2011, Measuring colors, $4^{\text {th }}$ Edition, Wiley and Sons Ed., West Sussex, UK. 
Jin L., Li D., 2007, A switching vector median filter based on the CIELAB color space for color image restoration, Digit. Signal Process., 87: 1345-1354

Jung H., Sato T., 2013, Comparison between the color properties of whiteness index and yellowness index on the CieLab, Text. Color. Finish., 25: 241-246

Konaka R., Kasahara E., Dunlap W. C., Yamamoto Y., Chien K. C., Inoue M., 2001, Ultraviolet irradiation of titanium dioxide in aqueous dispersion generates singlet oxygen, Redox Report, 6: 319325.

Luo W., Westland S., Ellwood R., Pretty I., Cheunga V., 2009, Development of a whiteness index for dentistry, Journal Dent., 37: e21-e26

Pérez Md.elM., Ghinea R., Rivas M.J., Yebra A., Ionescu A.M., Paravina R.D., Herrera L.J., 2016, Development of a customized whiteness index for dentistry based on CIELAB color space, Dent Mater., 32: 461-467.

Porter S.C., Felton L.A., 2010, Techniques to assess film coatings and evaluate film-coated products - assessing film coatings and film-coated products, Drug Dev. Ind. Pharm. 36: 128-142.

Rajakumari R., Oluwafemi O.S., Thomas S., Kalarikkal N., 2018, Dietary supplements containing vitamins and minerals: Formulation, optimization and evaluation, Powder Technology, 336: 481-492.

Patton T. C., 1988, Pigment handbook, Volumes 1-3, Wiley \& Sons, London-UK.

Rowe R.C., 1984, The opacity of tablet film coatings, J. Pharm. Pharmacol., 36: 569-572

Sánchez-Marañón M., Delgado G., Melgosa M., Hita, E., Delgado R., 1997, CieLab color parameters and their relationship to soil characteristics in mediterranean red soils, Soil. Sci., 162: 833-842.

Sauer D., Cerea M., Dinunzio J., McGinity J., 2013, Dry powder coating of pharmaceuticals: A review, Int. J. Pharm., 457: 488-502. 
Seo K.-S., Bajracharya R., Lee S.H., Han H.-K., 2020, Pharmaceutical application of tablet film coating, Pharmaceutics, 12: 853.

Sharma G. Ed., 2003, Digital Color imaging handbook, CRC press, Taylor \& Francis group, London UK

Titanium dioxide For coatings - Ti-Pure ${ }^{\mathrm{TM}}$, product overview, https://www.tipure.cn//media/files/tipure/legacy/titanium-dioxide-for-

coatings.pdf?rev=70975dd1245f4082841a13ef41058282, last access on January 5, 2022

Weatherall I.L., Lee W.G., 1991, Instrumental evaluation of some New Zealand fruit colours using CIELAB values, 29: 197-205

Weatherall I.L., Coombs B.D., 1999, Skin color measurements in terms of CieLlab color space values, J. Investig. Dermatol. 99: 468-473.

Webster M.A., Malkoc G., Bilson A. C., Webster S.M., 2002, Color contrast and contextual influences on color appearance, J. Vis., 2: 6.

Winkler H.C., Notter T., Meyer U., Naegeli H., 2018, Critical review of the safety assessment of titanium dioxide additives in food, J. Nanobiotechnology, 16: 1

Younes M., Aquilina G., Castle L., Engel K.-H., Fowler P., Frutos Fernandez M.J., Furst P., GundertRemy U., Gürtler R., Husøy T., Manco M., Mennes W., Moldeus P., Passamonti S., Shah R., Waalkens-Berendsen I., Wölfle D., Corsini E., Cubadda F. De Groot D., FitzGerald R., Gunnare S., Christian Gutleb A., Mast J., Mortensen A., Oomen A., Piersma A., Plichta V., Ulbrich B., Van Loveren H., Benford D., Bignami M., Bolognesi C., Crebelli R., Dusinska M., Marcon F., Nielsen E., Schlatter J., Vleminckx C., Barmaz S., Carfı M., Civitella C., Giarola A., Rincon A.M., Serafimova R., Smeraldi C., Tarazona J., Tard A., Wright M., 2021, Safety assessment of titanium dioxide (E171) as a food additive, EFSA J., 19: 6585 
Zaid A.N., 2020, A comprehensive review on pharmaceutical film coating: past, present, and future, Drug Des. Devel. Ther., 14: 4613-4623. 
Figure 1.tif
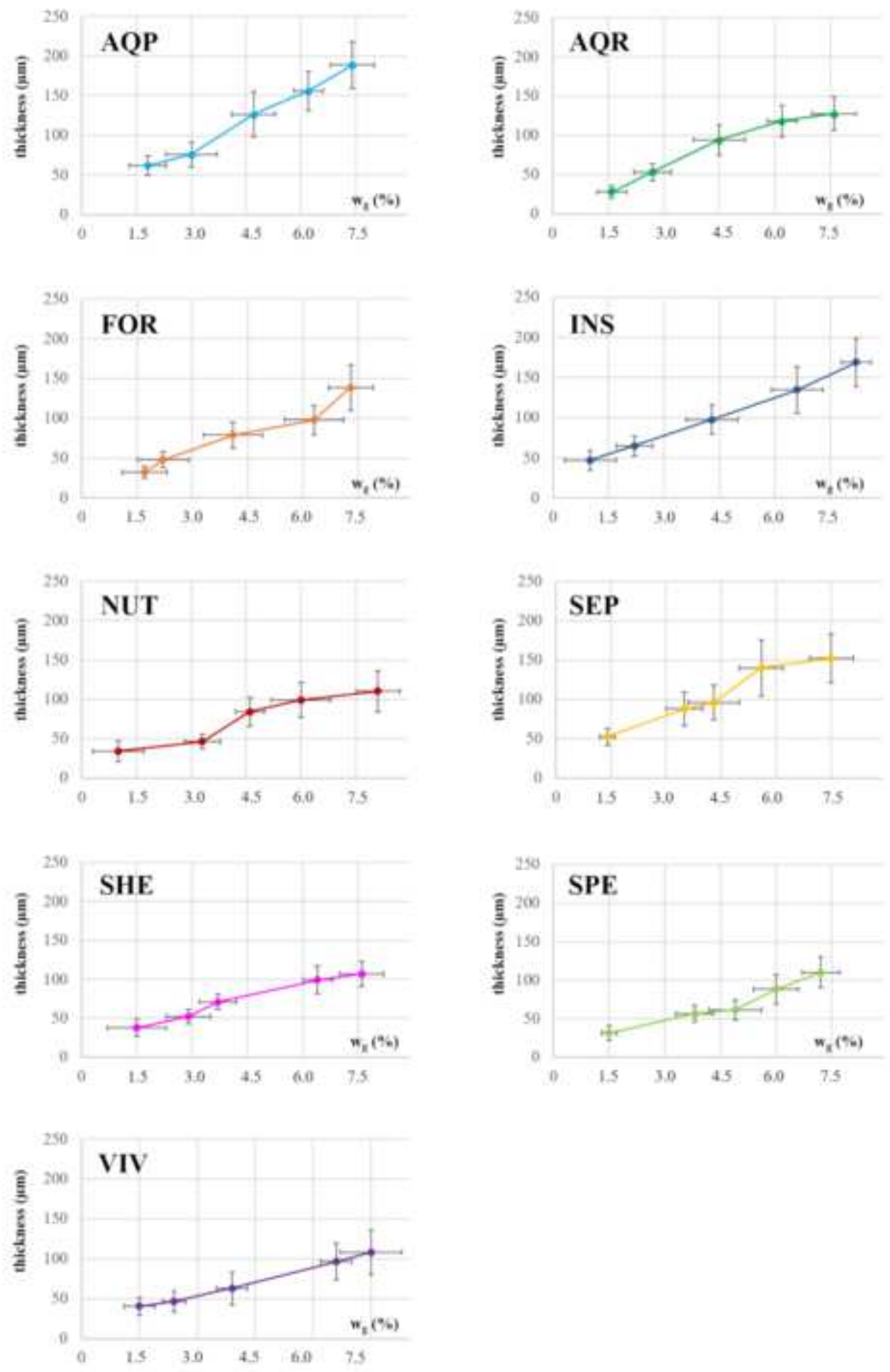


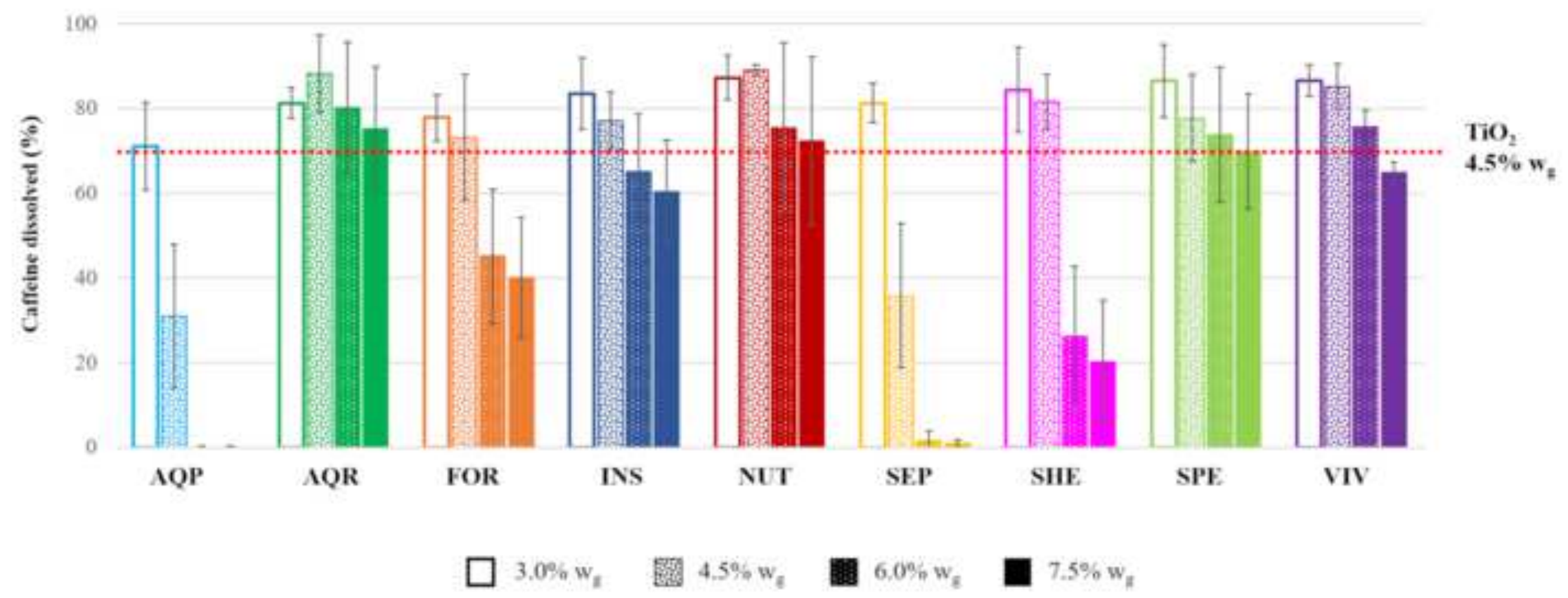

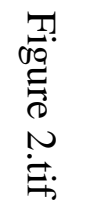

$\mathrm{TiO}_{2}$ $4.5 \% \mathrm{w}_{\mathrm{z}}$

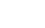


Figure 3.tif

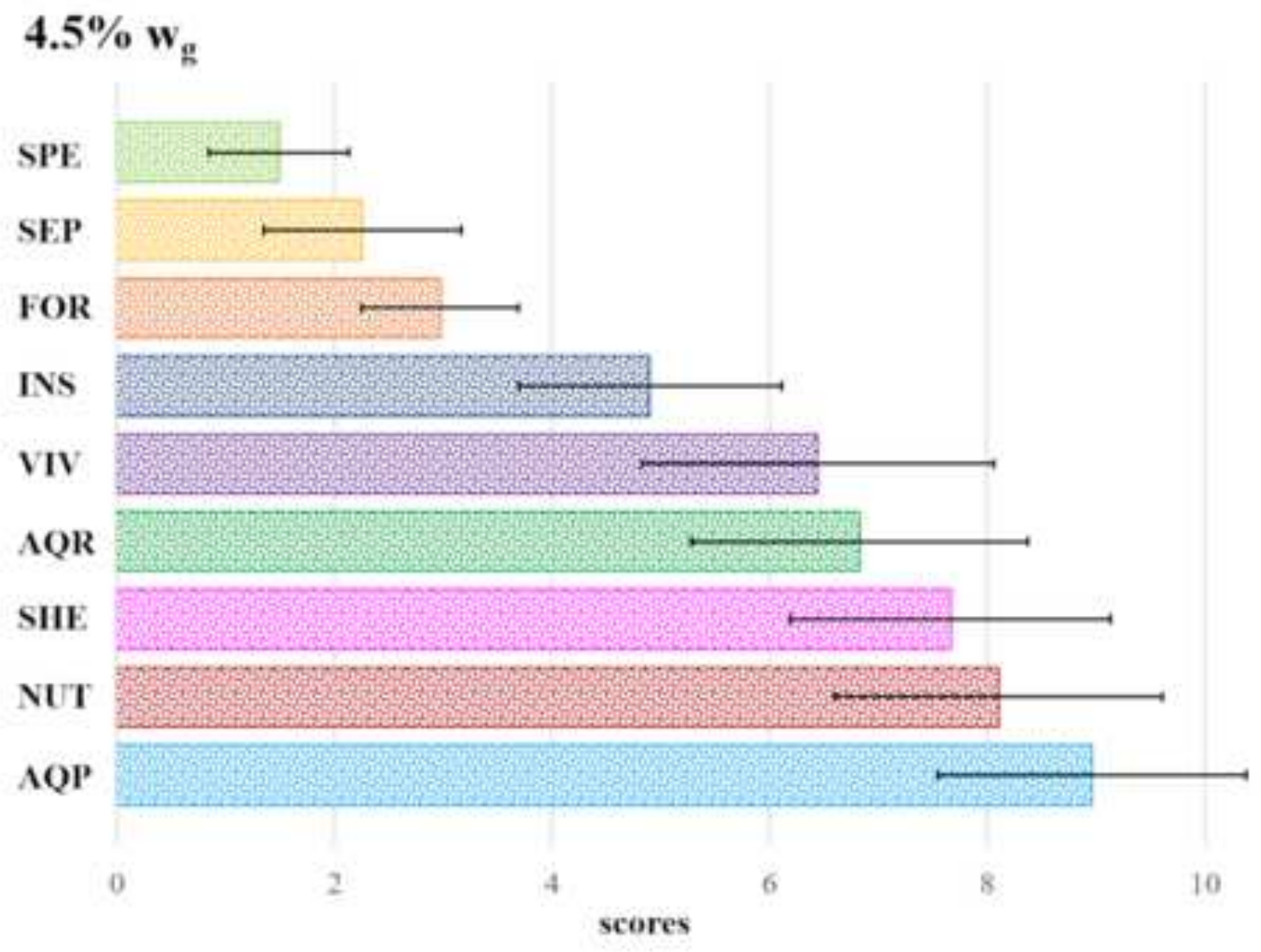

\section{$7.5 \% w_{g}$}

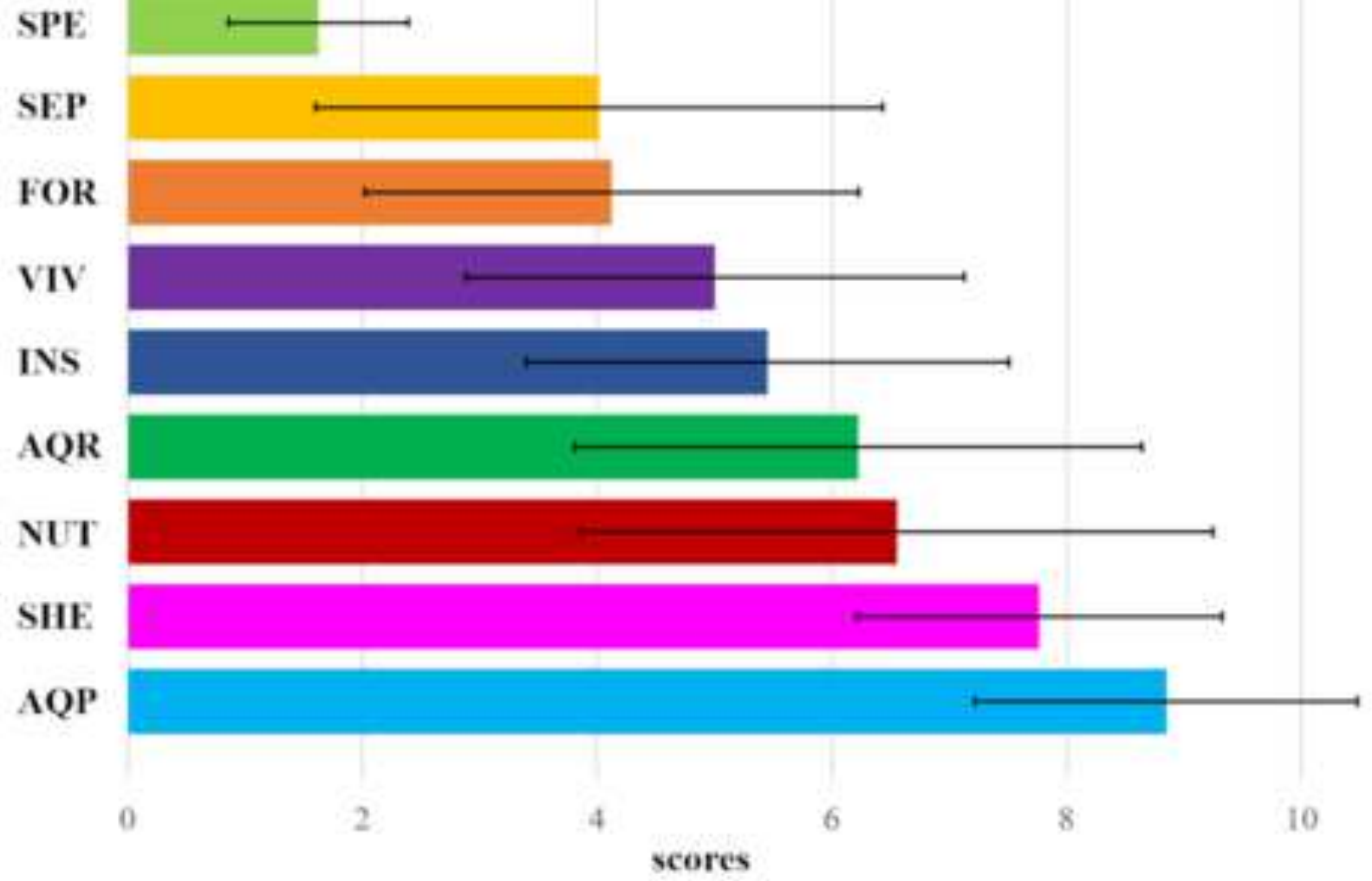



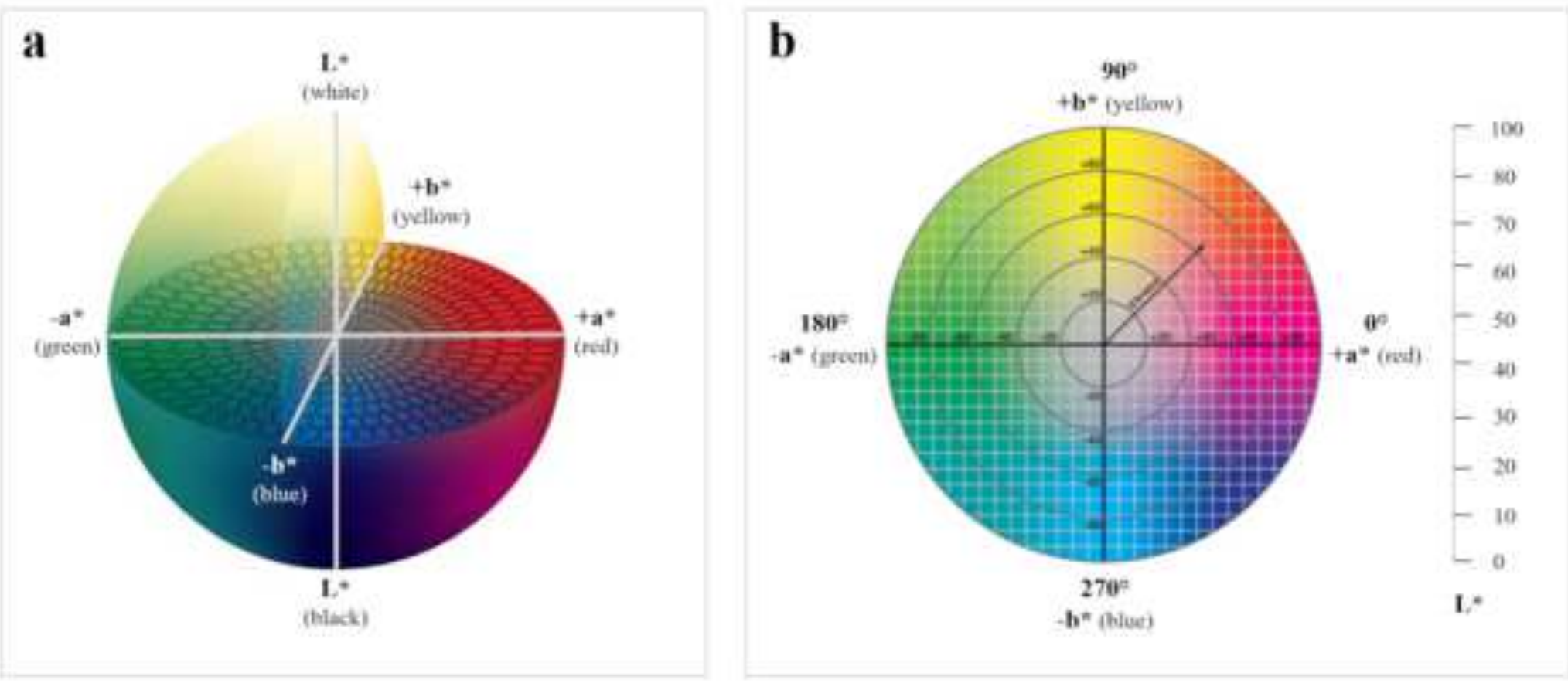

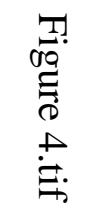

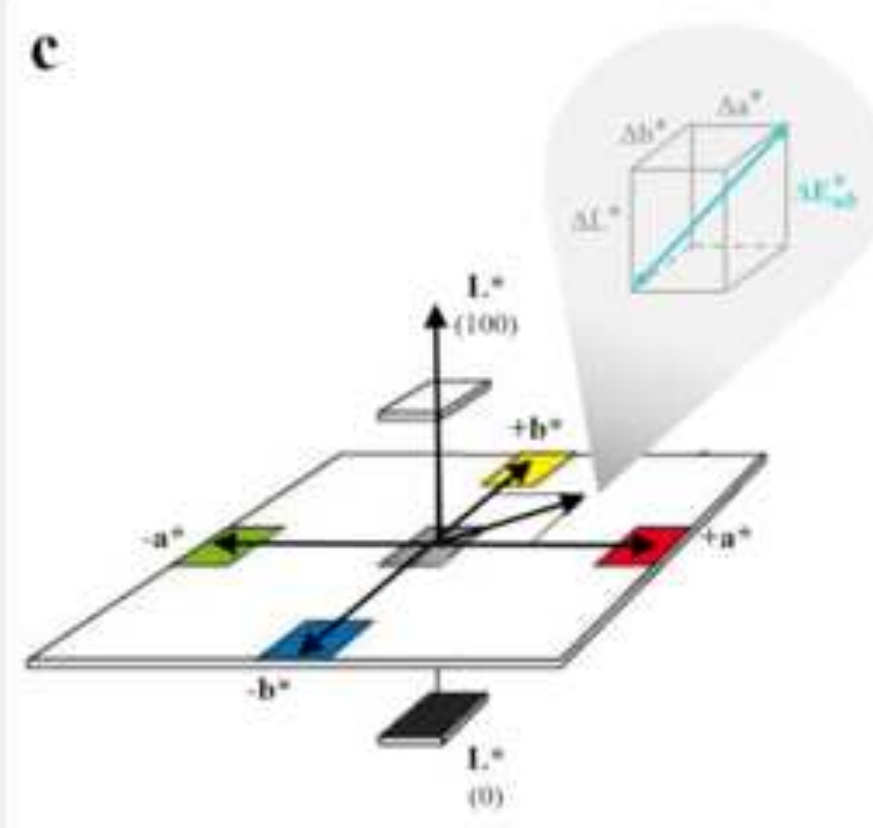

d

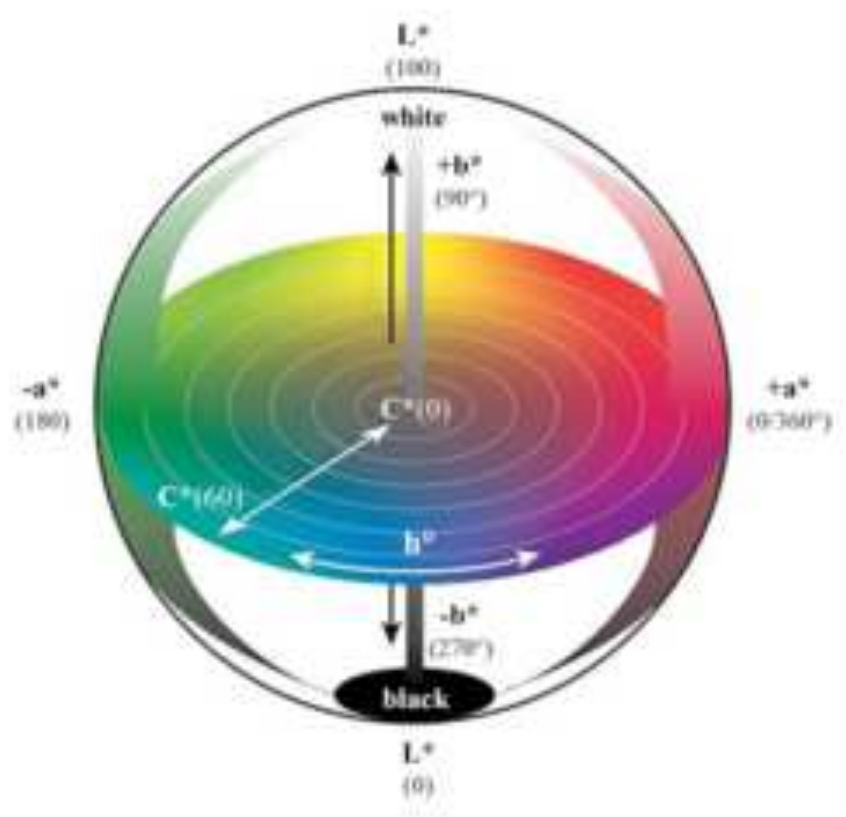


Palugan L. et al., Figure 5 revised.tif
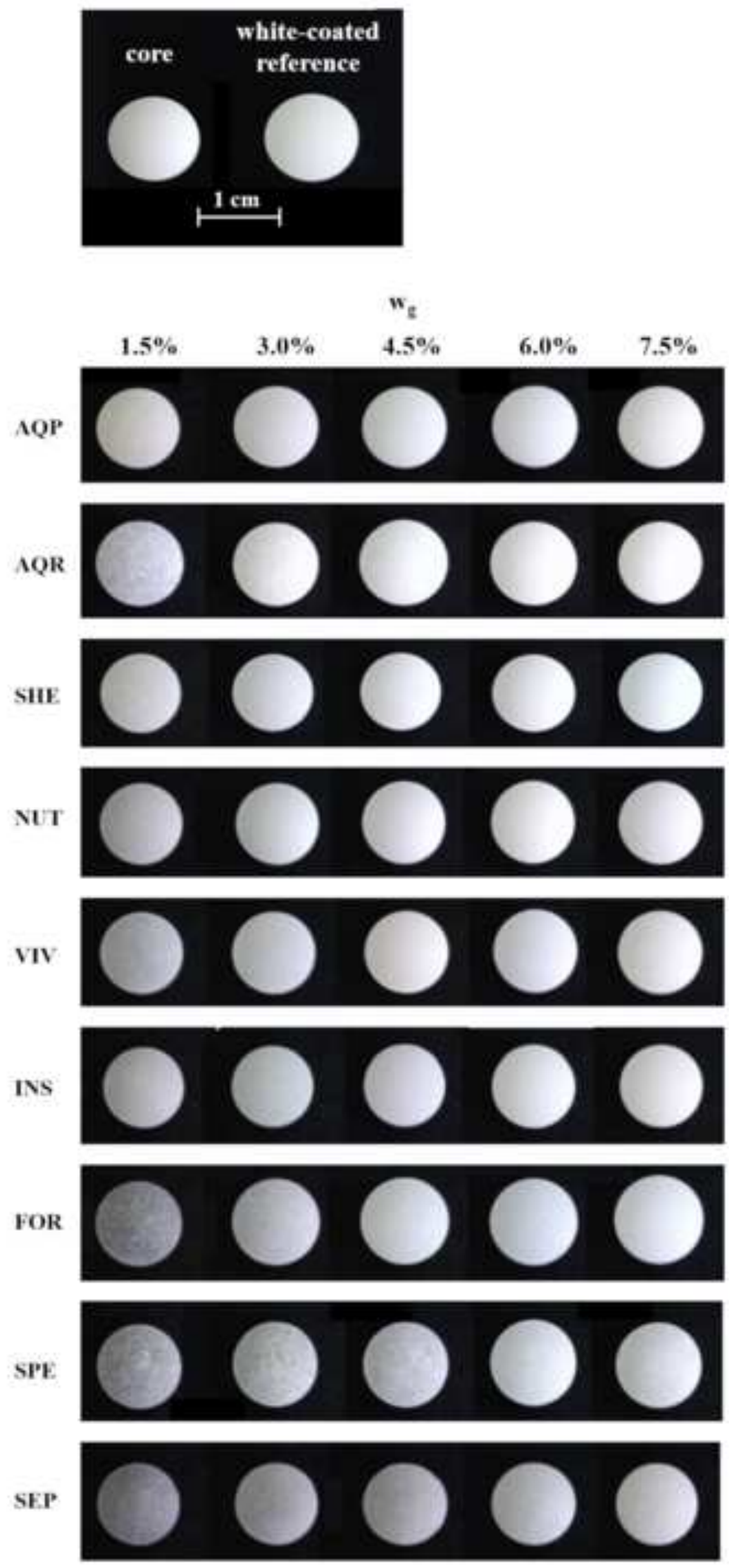
Figure 6.tif
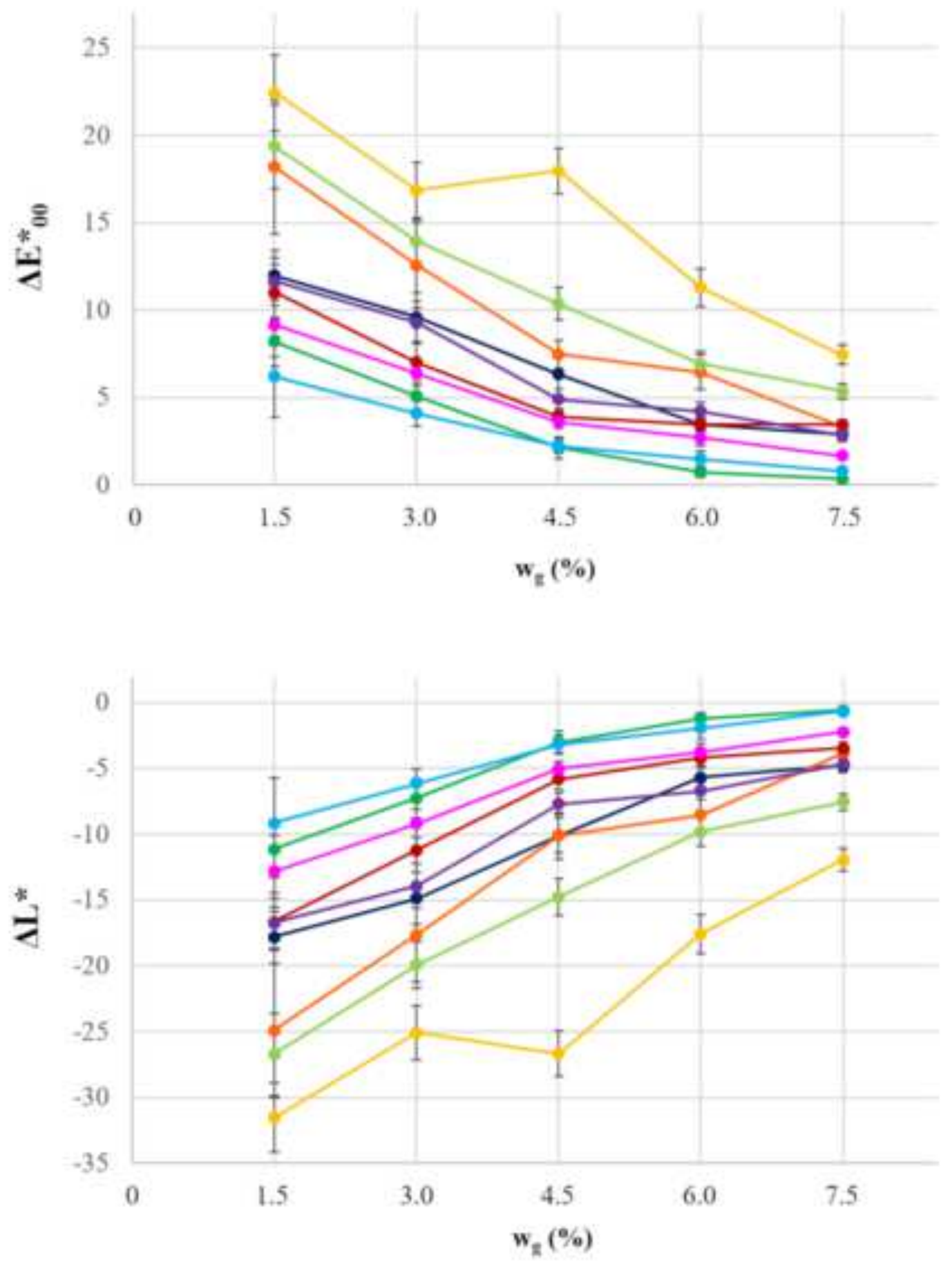

IIEP

SPE

FOR

INS

VIV

NUT

SHE

I $\mathrm{AQR}$

AQP

$$
\text { - }
$$

P




\section{Declaration of interests}

The authors declare that they have no known competing financial interests or personal relationships that could have appeared to influence the work reported in this paper.

$\bigotimes$ The authors declare the following financial interests/personal relationships which may be considered as potential competing interests:

We wish to draw the attention of the Editor to the following:

- $\quad$ the data reported in this work partly refer to tablets coated in Euronovis s.r.l. and evaluated in terms of white color using a spectrophotometer provided by N.G. Labtech s.r.I.

- M. Spoldi and F. Rizzuto wish to disclose that they are employees of Euronovis s.r.l., while N. Guerra works for N.G. Labtech s.r.l.

We wish to confirm that there has been no financial support for this work that could have influenced its outcome. Moreover, Euronovis s.r.I. and N.G. Labtech s.r.I. did not provide any funding for the present scientific study. 


\section{$\underline{\text { CRediT author statement }}$}

- Luca Palugan (L.P): Writing - Original Draft; Conceptualization; Formal analysis; Investigation

- Mattia Spoldi (M.S.): Writing - Review \& Editing; Conceptualization; Supervision

- Francesco Rizzuto (F.R.): Investigation; Methodology

- $\quad$ Norberto Guerra (N.G.): Writing - Review \& Editing; Conceptualization; Investigation

- Marco Uboldi (M.U.): Data Curation; Visualization

- Matteo Cerea (M.C.): Methodology; Visualization

- Saliha Moutaharrik (S.M.): Formal analysis; Data Curation

- $\quad$ Alice Melocchi (A.M.): Writing - Original Draft; Writing - Review \& Editing; Data Curation; Project administration

- $\quad$ Andrea Gazzaniga (A.G.): Resources

- $\quad$ Lucia Zema (L.Z.): Writing - Review \& Editing; Resources; Supervision 